Universidad de Lima

Facultad de Economía

Carrera de Economía

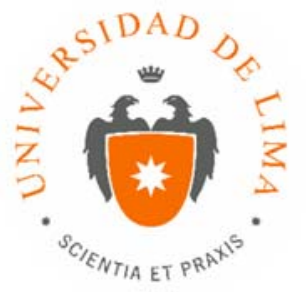

\title{
EFECTO DE LOS MULTIFONDOS SOBRE EL SISTEMA PRIVADO DE PENSIONES PERUANO Y LA INVERSIÓN NACIONAL EN EL PERIODO 2007-2014
}

Trabajo de investigación para optar el título profesional de economista

\section{Lilian Angelica Bonilla Vilchez}

20100155

\author{
Asesor \\ Ricardo Manuel Padilla Casaverde
}

Lima - Perú

Febrero de 2017 



\section{EFECTO DE LOS MULTIFONDOS SOBRE EL SISTEMA PRIVADO DE PENSIONES PERUANO Y LA INVERSIÓN NACIONAL EN EL PERIODO 2007-2014}




\section{TABLA DE CONTENIDO}

INTRODUCCIÓN .1

CAPÍTULO I: MARCO TEÓRICO ..............................................................4

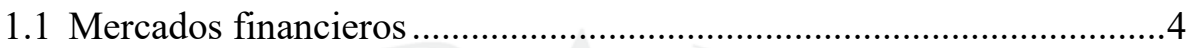

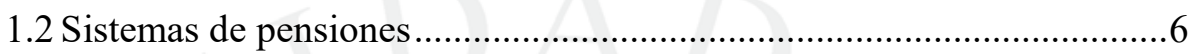

1.3 Importancia de los sistemas de pensiones........................................

1.4 Teoría del ciclo de vida y diversificación temporal ...............................8

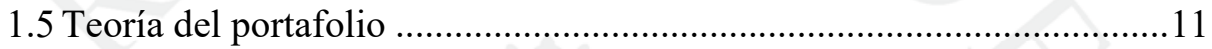

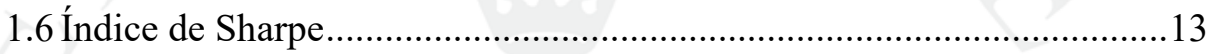

1.7 Paradoja de Feldstein-Horioka............................................................ 14

CAPÍTULO II: SISTEMA PRIVADO DE PENSIONES EN EL PERÚ ...........16

2.1 Regímenes de pensiones en el Perú ......................................................16

2.1.1 El Sistema Nacional de Pensiones ................................................ 17

2.1.2 La reforma de 1993: Creación del Sistema Privado de Pensiones...19

2.2 Evolución del Sistema Privado de Pensiones .........................................21

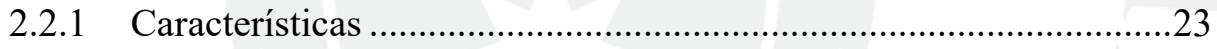

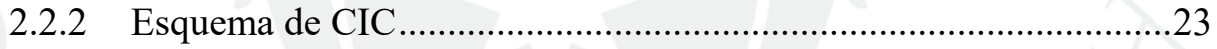

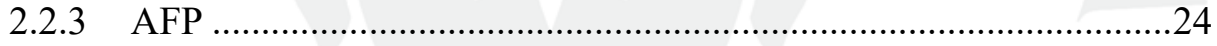

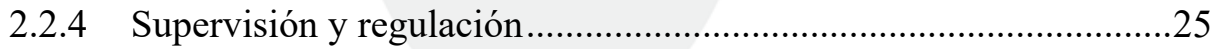

2.3 La reforma de 2005: Multifondos .........................................................26

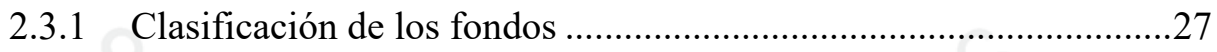

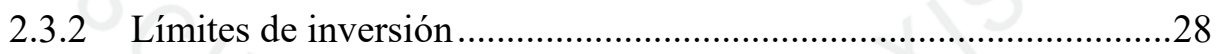

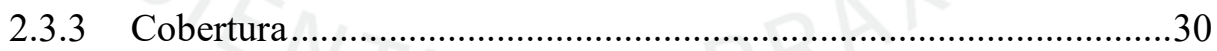

2.3.4 Desempeño de los fondos............................................................ 31

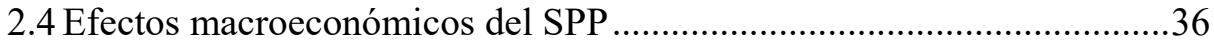

2.4.1 Vinculación con el ahorro nacional................................................36

2.4.2 Vinculación con la inversión nacional ...........................................37

CAPÍTULO III: EL EFECTO DE LOS MULTIFONDOS EN EL SISTEMA PRIVADOR DE PENSIONES Y LA INVERSIÓN PERUANA .........................40

3.1 Elección de variables ....................................................................40 
3.2.1 Efecto sobre el Sistema Privado de Pensiones ................................41

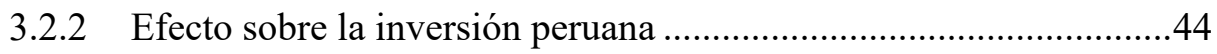

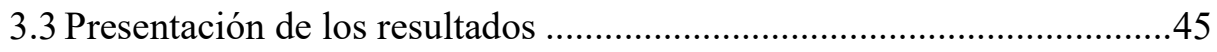

3.3.1 Comparación de escenarios planteados..........................................45

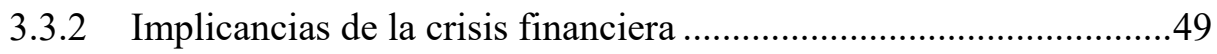

3.3.3 Paradoja de Feldestein-Horioka ...................................................51

3.4 Análisis de proyecciones y tendencias................................................54

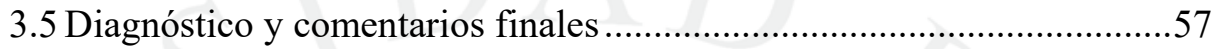

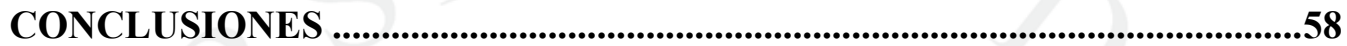

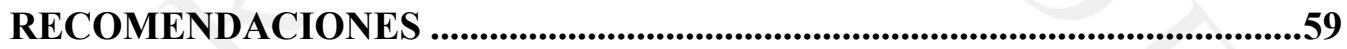

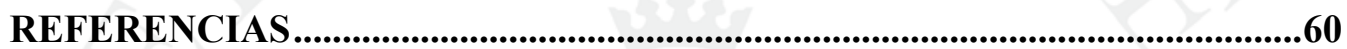

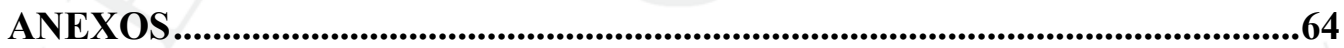




\section{ÍNDICE DE TABLAS}

Tabla 1.1: Estructura de los mercados financieros .5

Tabla 2.1: Rendimiento real promedio de los fondos de la seguridad social en cinco países latinoamericamos durante la década de 1980 .18

Tabla 2.2: Límites máximos según Tipo de Fondo en el esquema Multifondos . .29

Tabla 2.3: Consolidado de la Cartera Administrada según Instrumento Financiero .....32

Tabla 2.4: Distribución de Afiliados por Tipo de Fondo y por Rango de Edad ..............35

Tabla 3.1: Descripción de variables utilizadas para el análisis...................................41

Tabla 3.2: Periodo ex-ante, ex-post crisis financiera ................................................50

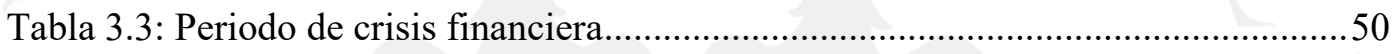

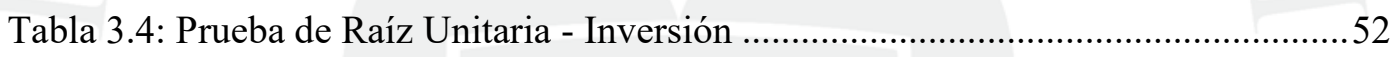

Tabla 3.5: Prueba de Raíz Unitaria - Cartera Administrada SPP..................................52

Tabla 3.6: Prueba de Raíz Unitaria - Ahorro Público ....................................................52

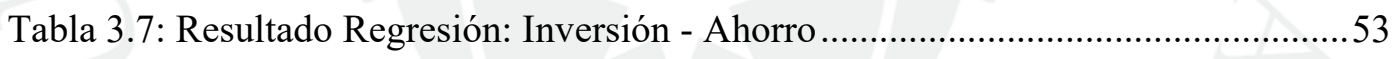

Tabla 3.8: Proyecciones anuales de la inversión total ............................................54 


\section{ÍNDICE DE FIGURAS}

Figura 1.1: Proceso del círculo virtuoso de la economía ........................................... 8

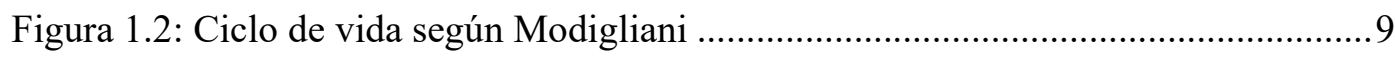

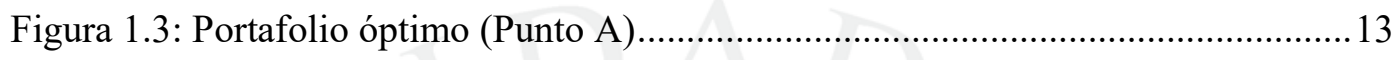

Figura 2.1: Evolución de la Cartera Administrada por el SPP ...................................22

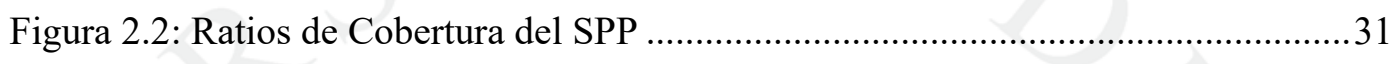

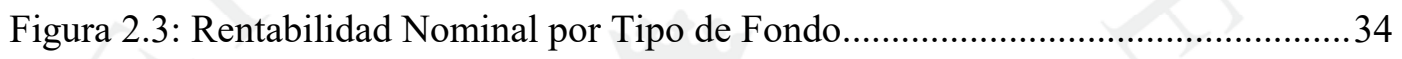

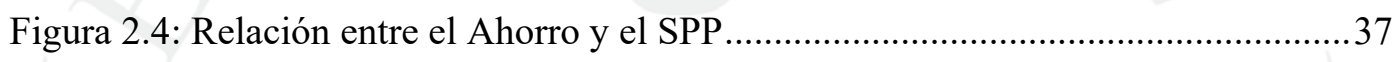

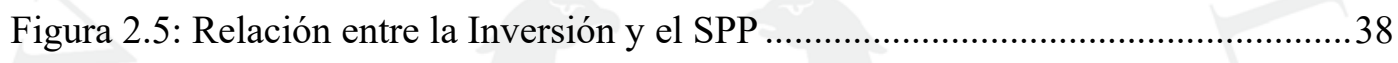

Figura 3.1: Escenarios planteados para el análisis.............................................. 42

Figura 3.2: Rentabilidad mensual de cada escenario ............................................. 46

Figura 3.3: Comparación del Índice de Sharpe ........................................................ 46

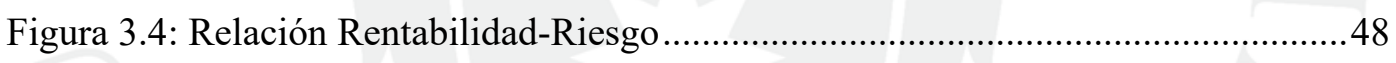

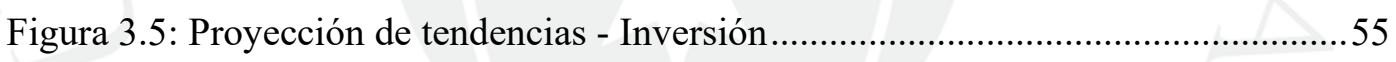

Figura 3.6: Proyección de tendencias - Cartera Administrada del SPP ........................56 


\section{ÍNDICE DE ANEXOS}

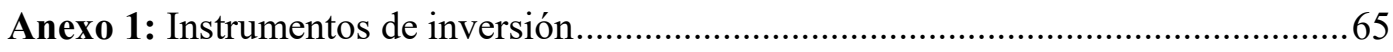

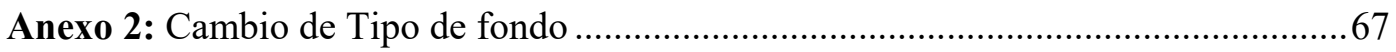

Anexo 3: Metodología para el efecto sobre el SPP .................................................69

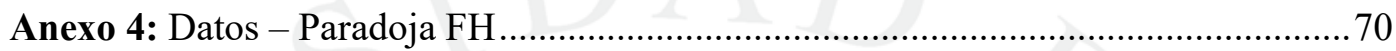

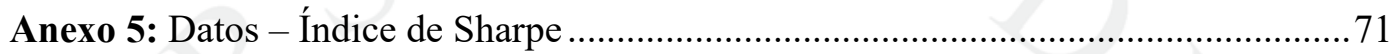




\section{INTRODUCCIÓN}

El Sistema Privado de Pensiones peruano (SPP) fue creado en 1992 mediante el Decreto Ley $\mathrm{N}^{\circ} 25967$ e inició sus operaciones en junio de 1993, doce años después que Chile y fue el segundo país en adoptar este sistema en Latinoamérica, dicha Ley corresponde al esquema de protección social a los trabajadores en materia de pensiones. El interés principal del nuevo régimen pensionario fue el reestructurar completamente el sistema existente, a fin de que el fondo sea individual y autofinanciado por el propio trabajador mediante Cuentas Individuales de Capitalización para cada contribuyente. En diciembre del 2005 entra en vigencia el régimen Multifondos con el propósito de ofrecer alternativas de inversión para los cotizantes de acuerdo a sus preferencias por el riesgo y una participación más activa en la elección de su cartera de inversiones.

La presente investigación pretende evaluar las diferencias en rentabilidad que genera los Multifondos frente al Sistema anterior de Fondo Único para analizar el impacto de esta reforma en el SPP mediante la comparación de la rentabilidad obtenida utilizando los tres fondos con el que se obtendría si solo se hubiera mantenido solo el fondo único establecido al momento de la creación del SPP, el periodo analizado comprende los años 2007-2014.

La relevancia del tema elegido se centra en el importante crecimiento del SPP en función al volumen administrado y su relación con el PBI, y su importancia y los efectos a largo plazo en la relación futura consumo-ingreso de todos los afiliados. Asimismo, el exponer los aumentos en rentabilidad del uso de los Multifondos también podría direccionarse a un incremento en los fondos destinados a la inversión nacional y ahorro privado, generando efectos positivos no solo para los afiliados sino para la economía peruana.

Para llevar a cabo el análisis del tema se ha planteado como objetivo general el siguiente: Comparar las rentabilidades obtenidas en el Sistema Privado de Pensiones peruano por medio de los Multifondos (Fondo Tipo 1, Fondo Tipo 2 y Fondo Tipo 3) y las obtenidas solo con el Fondo Único (Fondo Tipo 2) desde el año 2007 al 2014 con la 
finalidad de evaluar el impacto positivo de este nuevo esquema en el sistema pensionario y en la inversión nacional.

Este objetivo general se desglosa en los siguientes objetivos específicos:

1. Identificar las principales contribuciones conceptuales sobre el sistema pensionario, los Multifondos, el ciclo de vida y las teorías económicas con el propósito de presentar el contexto y sustento teórico adecuado para la investigación.

2. Evaluar la evolución de las rentabilidades promedio de los tres tipos de fondos y la composición de la cartera administrada a fin de establecer que una buena estrategia de inversión utilizando los tres tipos de fondos disponibles que satisfaga las necesidades riesgo-retorno del afiliado e incremente su fondo pensionario y el valor de su futura pensión.

3. Analizar el efecto del Sistema Privado de Pensiones, mediante el ahorro obligatorio que este genera a partir de los aportes de los afiliados, en la inversión nacional con el fin de cuantificar el efecto macroeconómico de este régimen.

Con el fin de alcanzar los objetivos planteados se formuló la siguiente hipótesis general: En el Sistema Privado de Pensiones peruano, los Multifondos ofrecen una rentabilidad mayor frente a la alternativa anterior de Fondo Único en el periodo que comprende desde el año 2007 al 2014 porque permiten crear una mejor estrategia de inversión y diversificar el riesgo mediante la utilización de los tres fondos según las características y preferencias del afiliado, lo que permite que el ahorro privado y la inversión nacional aumente.

Al igual que con el objetivo general, la hipótesis general está acompañada de hipótesis específicas:

1. Acompañar el ciclo de vida del trabajador con el uso de las tres alternativas que los Multifondos ofrece maximiza la rentabilidad obtenida al final del periodo y se acomoda a las preferencias de cada etapa, incrementando los montos invertidos y la futura pensión del afiliado.

2. El ahorro obligatorio generado como consecuencia de los aportes al Sistema Privado de Pensiones en sus diferentes tipos de fondos impacta positivamente en la inversión nacional al destinar parte de sus inversiones en instrumentos locales, lo cual favorece el crecimiento económico del país. 
A modo de ayudar al lector con la comprensión del análisis se ha divido la investigación en tres capítulos. En el primer capítulo se exponen los conceptos y teorías generales más importantes relacionadas con el tema a tratar, de esta manera de esclarecer el primer objetivo específico. En el segundo capítulo se profundiza en el sistema pensionario, pero aplicado con mayor detalle a la realidad peruana y se agrega evidencia empírica que nos permita alcanzar los objetivos planteados.

Finalmente en el tercer capítulo se contrastan las hipótesis específicas mediante la aplicación de indicadores seleccionados como el índice de Sharpe y la ecuación de Feldstein-Horioka; primero para poder cuantificar el efecto del esquema Multifondos se utilizarán dos escenarios para el mismo periodo de análisis: En el primero se utilizará solo el Fondo Tipo 2 simulando que la norma de los esquemas de fondos múltiples no se hubiera promulgado; y en el segundo se utilizarán los tres fondos disponibles actualmente en el sistema Multifondos; y luego para hallar el impacto en la inversión peruana se tomarán los aportes obligatorios de los afiliados al SPP como parte del ahorro privado como variable importante en la ecuación econométrica y se evaluará el coeficiente resultante. 


\section{CAPÍTULO I: MARCO TEÓRICO}

El presente capítulo pretende identificar las principales contribuciones conceptuales del tema ya que es preciso conocer el sustento teórico para realizar un análisis adecuado de los Fondos de Pensiones.

Primero para poner en contexto al lector se presentan las definiciones de los mercados financieros y de los Sistemas de Pensiones, luego se describe la importancia de los mismos para la economía de un país. A continuación, se describen las teorías desarrolladas por Modigliani y Markowitz sobre el ciclo de vida y la gestión de portafolios respectivamente para resaltar la relevancia y los efectos económicos de estos sistemas. La teoría de Modigliani ejemplifica el comportamiento adecuado del ahorro a lo largo del ciclo vital para mantener consumos constantes incluso cuando la persona ya no genera ingresos. Por otro lado, la teoría de Markowitz señala la existencia simultánea de rentabilidad y riesgo en los portafolios de inversión y como es que los agentes racionales tienden a maximizar sus carteras hallando el punto eficiente de inversión.

Del mismo modo, se presenta el indicador creado por William Sharpe para evaluar el desempeño retorno-riesgo de una cartera y la paradoja de Feldstein-Horioka sobre la relación entre el ahorro y la inversión doméstica; temas que en los capítulos siguientes serán utilizados para cumplir los objetivos planteados y contrastar las hipótesis de la investigación.

\subsection{Mercados financieros}

Mishkin (2014) define a los mercados financieros como aquellos espacios virtuales o físicos donde se transfieren fondos desde agentes económicos que poseen un exceso de fondos disponibles, hacia quienes que tienen escasez de los mismos; por lo son fundamentales para promover mayor eficiencia económica al canalizar fondos desde quienes no los usan de manera productiva, hacia quienes si lo hacen. 
El correcto funcionamiento de los mismos es un factor crítico para la economía ya que no solo fomenta la asignación eficiente del ahorro a los proyectos de inversión, sino que también impulsa una mayor tasa de ahorro e inversión y es vital para que un país logre un crecimiento a largo plazo. (Krugman, 2011, p. 222)

\section{Tabla 1.1}

Estructura de los mercados financieros

\begin{tabular}{|c|c|}
\hline \multirow{2}{*}{ Criterio } & Clasificación \\
\hline \multirow{2}{*}{ Naturaleza } & Mercado de deuda \\
\cline { 2 - 2 } Madurez (Fase de negociación) & Mercado de acciones \\
\cline { 2 - 2 } & Mercado primario \\
\hline \multirow{2}{*}{ Estructura Organizacional } & Mercado secundario \\
\cline { 2 - 2 } & Mercado bursátil \\
\cline { 2 - 2 } & Mercado de subasta \\
\hline \multirow{2}{*}{ Vencimiento } & Mercado de capitales \\
\cline { 2 - 2 } & Mercado de dinero \\
\hline \multirow{2}{*}{ Entrega } & Mercado spot \\
\hline \multirow{2}{*}{ Grado de intervención } & Mercado de derivados \\
\cline { 2 - 2 } & Mercado libre \\
\cline { 2 - 2 } & Mercado regulado \\
\hline \multirow{2}{*}{ Formalización } & Mercado organizado \\
\cline { 2 - 2 } & Mercado no organizado \\
\hline
\end{tabular}

Fuente: Martín, M. J. L., \& Trujillo, P. A. (2004). Manual de mercados financieros, pág. 24

Sin embargo, esta efíciencia económica se ve afectada por la existencia de información asimétrica la cual actúa como una barrera para la asignación eficiente de capital creando fricciones financieras. Cuando estas fricciones se vuelven frecuentes, los mercados financieros pierden esta capacidad de transmitir los fondos de los agentes ahorradores a empresas y hogares con oportunidades de inversión. Esta situación podría ser el punto de inicio para que ocurra una crisis donde los mercados dejan de funcionar y la actividad económica colapsa. 


\subsection{Sistemas de pensiones}

Los Sistemas de Pensiones forman parte de las medidas de Seguridad Social ${ }^{1}$, definida por la Organización Internacional del Trabajo (OIT, 1991) como:

La protección que la sociedad proporciona a sus miembros, mediante una serie de medidas públicas contra las privaciones económicas y sociales que, de no ser así ocasionarían la desaparición o una fuerte reducción de los ingresos por causa de enfermedad, maternidad, accidente de trabajo o enfermedad laboral, desempleo, invalidez, vejez y muerte; y también la protección en forma de asistencia médica y de ayuda a las familias con hijos. (p. 9)

Los sistemas pensionarios pertenecen al grupo relacionado con la previsión al enfocarse en que el trabajador perciba un ingreso luego de su retiro del mercado laboral. El concepto de sistemas de pensiones es mucho más particular y específico que el de seguridad social; asimismo este último implica necesariamente la participación del Estado (financista o administrador), mientras que los sistemas pensionarios pueden ser públicos, privados, o una combinación de ambos, y son las contribuciones de los trabajadores generalmente la fuente de financiamiento.

Whitehouse (2007) señala que la tipología de los sistemas de pensiones es muy variada y que ha llegado a ser muy confusa. Debemos notar que esto resulta del hecho de que su clasificación puede hacerse según diversos criterios: Obligatorios o voluntarios, de acuerdo con el grado de financiamiento por parte de los trabajadores, el tipo de administración (pública o privada), sistemas únicos o variados y de acuerdo a su origen. (p. 5)

Siguiendo la nueva tipología del Banco Mundial (2005), adicionalmente a los tres pilares básicos sobre lo que se puede organizar un sistema de pensiones (Sistema público de reparto, Sistema de capitalización individual y Planes ocupacionales), se han agregado otros dos pilares (pilar 0 para abordar más específicamente el objetivo de prevención de pobreza y el pilar no fondeado para incluir el contexto más amplio de la política social)2:

- Pilar Cero: No contributivo en forma de demogrant (beneficio universal fijo, monto de dinero asistencial basado solamente en la edad y la

\footnotetext{
${ }^{1}$ El concepto de Seguridad Social surge en Alemania en el siglo XIX, impulsada por el Canciller Alemán Otto Von Bismarck.

${ }^{2}$ En la práctica los sistemas de pensiones pueden combinar dos o más pilares para satisfacer de manera adecuada las necesidades de sus habitantes.
} 
residencia) o pensión social de financiamiento público que provee un mínimo nivel de protección.

- Primer Pilar: Sistema contributivo, obligatorio y público que varía gradualmente con el ingreso y busca reemplazar alguna porción del ingreso, posee un componente redistributivo y es generalmente de beneficios definidos.

- Segundo Pilar: Obligatorio de administración privada (cuenta de ahorro individual constituida en una variedad de formas) que busca reemplazar el ingreso y principalmente de contribución definida.

- Tercer Pilar: Arreglos voluntarios de administración privada de planes individuales, colectivos, financiadas por el empleador, de beneficios definidos o de contribución definida. Son esencialmente flexibles y de naturaleza discrecional.

- Cuarto Pilar: Fuentes de apoyo, informal, intrafamiliar o intergeneracional; pueden ser activos financieros (cuentas de ahorro, inversiones, seguros de largo plazo, transferencias) o no financieros (propiedades, bienes, otros activos físicos). Incluye acceso a salud y vivienda para ancianos.

\subsection{Importancia de los sistemas de pensiones}

Los países instauraron el Sistema de Pensiones como mecanismo de previsión que busca entregar a sus afiliados una pensión para la jubilación como resultado de los aportes realizados en el periodo laboral activo. Asimismo, se busca cumplir con el objetivo del Banco Mundial que establece que estos regímenes deben procurar que el pensionario pueda mantener un consumo que satisfaga sus necesidades y que no ingrese a una situación de pobreza.

Así como los regímenes de pensiones se relacionan con el consumo futuro de los pobladores y la prevención de un mayor nivel potencial de pobreza en años posteriores, estos fondos también interactúan con la economía mediante la fluctuación de la inversión pública o privada, movimientos en el ahorro nacional y el desarrollo de mercados financieros, impactando directamente en el desempeño económico del país y el bienestar de la población, formándose de este modo un círculo virtuoso; adquiriendo como 
resultado de esta dinámica una notoriedad significativa. "Los sistemas de pensiones operan en forma integrada con otros importantes componentes de la economía: el mercado de trabajo y sus instituciones; el sector público y sus instituciones, y los mercados financieros y de seguros y sus instituciones" (Uthoff, 1995, p. 56)

Figura 1.1

Proceso del círculo virtuoso de la economía

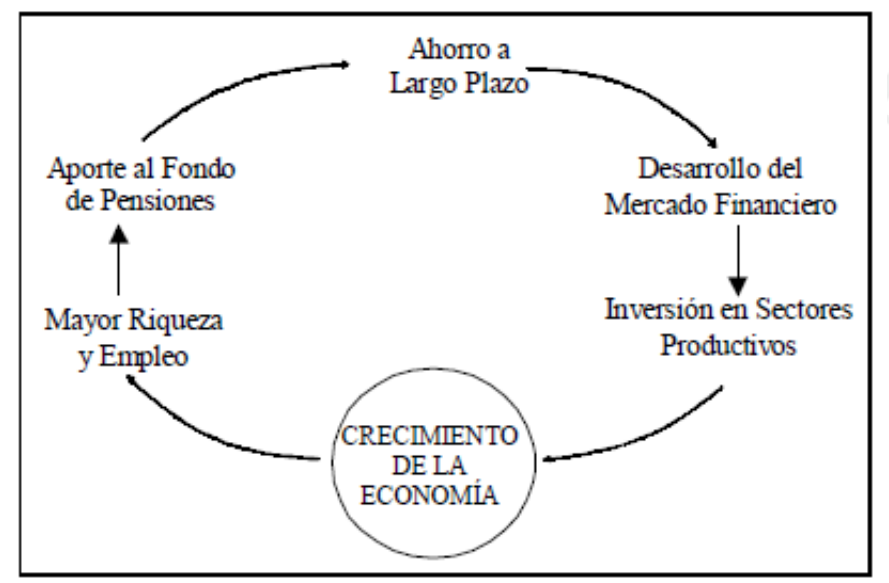

Fuente: Flores, W. (2005) La teoría de portafolio y la gestión de inversiones de los fondos de pensiones de Perú 1997-2002

Resaltando la importancia de los recursos que forman parte de los fondos de pensiones se analiza el manejo de los mismos durante el periodo anterior a su uso futuro como parte de las pensiones mediante diversas teorías e ideologías.

\subsection{Teoría del ciclo de vida y diversificación temporal}

Esta teoría, cuyo principal precursor fue Franco Modigliani (The Life Cycle Hypothesis of Saving, 1963), resalta la idea que cada sujeto cumple con un ciclo a lo largo de su vida económica, en particular en lo que concierne a sus ingresos. Este ciclo comienza con una etapa donde no percibe ingresos, luego continúa con su etapa laboral y finalmente se jubila. 
Como se muestra en la figura, De Gregorio (2007) diagrama el ciclo de vida del individuo desde el período en que comienza a ganar dinero. Lo primero que se debe recalcar, es que las personas intentan suavizar su consumo, ahorrando y desahorrando durante todo su ciclo vital, de esta manera logran un consumo constante; según esta teoría una persona intenta tener un consumo parejo durante su vida laboral y también durante su jubilación.

La trayectoria de ingresos descrita en el gráfico aumenta exponencialmente hasta lograr un monto máximo, luego va descendiendo discretamente hasta el momento de la jubilación donde cae a cero; a partir de este momento la persona hace uso de los ahorros que generó durante la etapa laboral para mantener el consumo constante hasta que finalmente fallece; es decir, consume todos sus ahorros y termina con cero activos.

Figura 1.2

Ciclo de vida según Modigliani

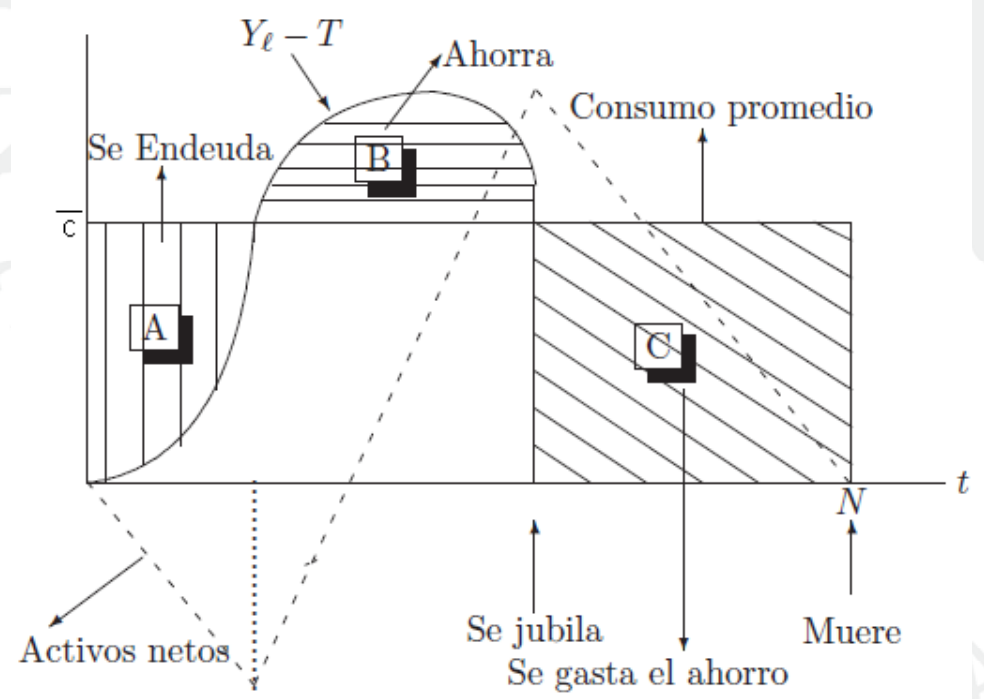

Fuente: De Gregorio, J. (2007). Macroeconomía: teoría y políticas

La formulación matemática del modelo afirma que el área laboralmente activa (B en la figura) debería ser igual a la suma de las áreas comprendidas antes y después del periodo laboral ( $\mathrm{A}$ y $\mathrm{C}$ ); esta afirmación del modelo original no toma en cuenta las tasas de interés, pero al tomarlas en cuenta se corrige la afirmación utilizando los valores 
presentes de cada etapa. Al suponer que el horizonte es finito, el individuo iría consumiendo, además del interés real, la acumulación de sus activos (stock de riqueza) a lo largo de su vida.

Uno de los puntos a resaltar de esta teoría es que el individuo al decidir su trayectoria de consumo, la que probablemente es constante a lo largo de la vida, debe planificar sus decisiones de ahorro con cautela considerando tanto sus ingresos actuales como los futuros ya que estos serán los únicos activos que posteriormente utilizará para mantener su mismo consumo en la etapa posterior a su jubilación.

En las palabras de Dornbush y Fischer (2008) la hipótesis del ciclo vital reflexiona sobre el argumento que los individuos planean sus niveles de consumo y ahorro en periodos prolongados, con la intención de distribuir su consumo de la mejor manera en el curso de toda su vida; así el ahorro previsional durante el periodo de trabajo tendría un mayor resultado a través de medidas que promovieran la integración a algún sistema de pensiones. (p. 321)

Nicholas Barr, del London School of Economics, afirma que la función económica de un sistema de pensiones es simplemente "suavizar" el nivel de consumo de los individuos en el largo plazo (life consumption smoothing), al hacer que los consumidores gasten menos durante su periodo de ingresos más altos, con el fin de que puedan gastar más durante su periodo de retiro y de bajos ingresos (Barr, 2004, p. 188)

Siguiendo la línea de este planteamiento teórico se encuentra la diversificación temporal porque incorpora el horizonte temporal relacionado con la edad y los años disponibles antes del cese del periodo laboral para lograr a la decisión de obtención de activos riesgosos al momento de invertir parte de los ahorros como variable adicional a la aversión al riesgo de un inversionista.

Kritzman (1994) especifica la diversificación temporal como la noción de que rendimientos que se encuentran por encima del promedio tienden a superar a aquellos que se localizan por debajo del promedio para horizontes temporales largos. En este sentido, la idea principal detrás de la diversificación temporal aduce que para los inversionistas con un horizonte temporal mayor les será más provechoso adquirir portafolios con activos más riesgosos ya que cuenta con una mayor capacidad de absorber el riesgo de pérdidas potenciales ante un retorno esperado mayor al tener más tiempo para compensar las pérdidas existentes con periodos de ganancias futuras o con un aumento adicional en sus ahorros sacrificando consumo actual; en cambio, quienes cuentan con 
horizontes más cortos no cuentan con esta misma capacidad de absorber pérdidas potenciales al disponer de menor tiempo para la inversión por ende prefieren activos más conservadores que presenten menores riesgos y conserven su valor sin fluctuaciones significativas.

De lo mencionado se infiere que no solo es preciso considerar la actitud frente al riesgo presentada en la teoría clásica de portafolio, sino que también es importante tomar en cuenta la capacidad del inversionista para tomar riesgo.

\subsection{Teoría del portafolio}

La Teoría del portafolio resultante de los estudios realizados por Harry Markowitz en 1952 (Portfolio Selection) y su posterior colaboración con James Tobin, William Sharpe y John Lintner en 1958 considera una varianza que mide la incertidumbre de los retornos y dos tipos de activos: Activos libres de riesgo o de renta fija, con una tasa de rentabilidad real conocida y constante; y activos riesgosos o de renta variable, con una tasa de retorno desconocida que cambia según la prima de riesgo y el periodo de inversión. Los inversionistas escogen el portafolio con base en el retorno esperado de sus activos, la varianza de cada uno de ellos y su disposición ante el riesgo. (p. 182)

Así, al escoger entre un número variado de portafolios que cuentan con un nivel de riesgo igual, el inversionista optará por el que genere un mayor retorno esperado, tal como lo afirma Markowits (1952) la regla de rentabilidad esperada-varianza establece que el inversionista debería querer optar por los portafolios que logren una combinación de retorno-varianza eficiente.

Según Herscovich (2003), el proceso de inversión está compuesto por dos aspectos importantes. El primero es el estudio del mercado y los instrumentos de inversión, para evaluar las características de riesgo y retorno esperado de un conjunto de instrumentos de inversión. El segundo es la formación de un portafolio óptimo, el cual está formado por la elección de las mejores alternativas disponibles de riesgo-rentabilidad y la determinación del portafolio óptimo.

Esta teoría se fundamenta en las siguientes ecuaciones para hallar el conjunto de carteras que maximizan la rentabilidad esperada aun riesgo dado o minimizan el riesgo a un nivel de rentabilidad establecido, también llamado carteras eficientes: 


$$
\operatorname{Max} E_{p}=\sum_{i=1}^{n} x_{i} E_{i} \quad \operatorname{Min}_{P}^{2}=\sum_{i=1}^{n} \sum_{j=1}^{n} x_{i} x_{j} \sigma_{i j}
$$

Considerando que:

$$
\sum_{i=1}^{n} x_{i}=1 \quad x_{i} \geq 1(i=1,2, \ldots, n)
$$

Donde $\mathrm{E}_{\mathrm{p}}$ es la rentabilidad esperada del portafolio $\mathrm{p} ; \sigma^{2}$ es la varianza del portafolio; x son los pesos de cada uno de los diferentes instrumentos que componen el portafolio; $\sigma_{\mathrm{ij}}$ es la covarianza entre los rendimientos de los instrumentos $\mathrm{i} / \mathrm{j}$-ésimos

Por tanto, el grupo de pares $\left[\mathrm{E}_{\mathrm{p}} ; \sigma^{2}\right]$ son las diversas combinaciones de retornoriesgo de todos los portafolios eficientes encontrados; es decir, todas aquellas que proporcionan el máximo rendimiento con un nivel de riesgo mínimo, y forman una curva cóncava que recibe el nombre de frontera eficiente.

Para determinar el portafolio óptimo de un inversionista se necesita establecer sus curvas de indiferencia, cuya forma dependerá de su función de utilidad y ésta será, naturalmente, diferente para cada inversionista. Al interceptar la curva de indiferencia del inversionista con la frontera de carteras eficientes se consigue el portafolio óptimo. No existe cartera en la frontera eficiente que domine alguna otra en esta misma curva, pero todos los que se encuentren sobre la misma dominarán a quienes estén por debajo de ésta, puesto que contarán con mayor rentabilidad al mismo nivel de riesgo, o menor riesgo al mismo nivel de rentabilidad.

Al analizar las diversas combinaciones de rentabilidad-riesgo, Sharpe (1974) define la Teoría de Portafolio como un modelo normativo; es decir, esta teoría se plantea con el objetivo de orientar al individuo en la toma de sus decisiones de inversión basándose en la diversificación de la incertidumbre y alienándose al espíritu de la frase ampliamente celebrada: "No ponga todos los huevos (la riqueza para invertir) en una misma canasta (mercado, instrumento o título de inversión)” (p. 357) para distribuir el riesgo incorporado a cada activo financiero en varias "canastas" de inversión. De modo que, si el valor de una canasta cae, la magnitud de la pérdida no será tan grande puesto que será compensada por la ganancia de las demás canastas. 
Figura 1.3

Portafolio Óptimo (Punto A)

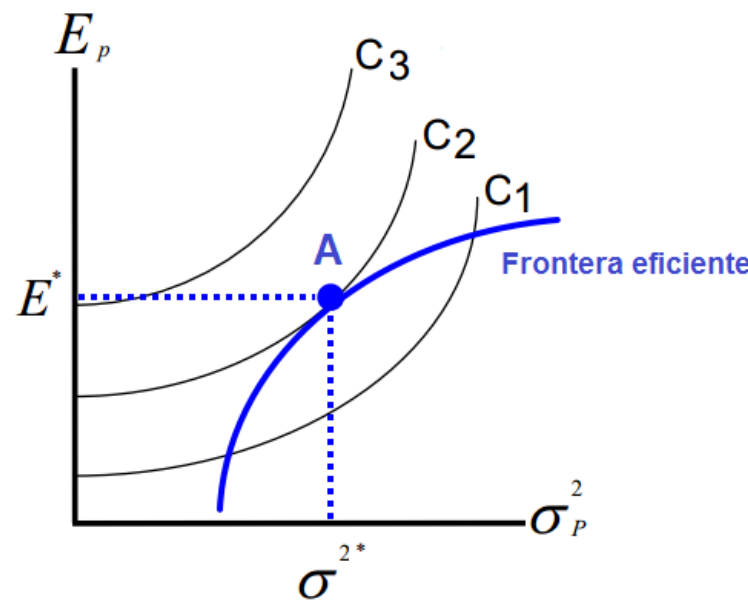

Fuente: Sharpe, W. (1976). Teoría de cartera y del mercado de capitales

\section{6 Índice de Sharpe}

Basado en el modelo de Markowitz, William F. Sharpe publica un modelo de selección de carteras con un supuesto básico de relacionar la rentabilidad con un determinado índice de mercado, introduciendo una subdivisión nueva del riesgo total: riesgo diversificable y riesgo sistémico propio del mercado; de esta manera logra reducir la complejidad del modelo anterior al ser usado en carteras con múltiples instrumentos.

El índice de Sharpe (Sp) es una medida del desempeño ajustada al riesgo que usa una referencia con base en la línea el mercado de capitales. Mide los rendimientos relativos al riesgo total de la cartera, donde el riesgo total es la desviación estándar de los rendimientos de la cartera. (Alexander, 2003, p. 125)

$$
S_{P}=\frac{E_{p}-R_{f}}{\sigma_{p}}
$$

Para lograr este resultado simultáneo de mayor rentabilidad y menor riesgo, William Sharpe ofreció una solución mediante esta herramienta que hasta el día de hoy se utiliza y es quizá una de las medidas más conocida para estudiar el desempeño de una activo o conjunto de activos por su simplicidad y buenos resultados, midiendo el exceso de rentabilidad por unidad de riesgo asumido que permite jerarquizar las alternativas de 
inversión teniendo en consideración las combinaciones de retorno-riesgo de cada una de ellas, por tanto mientras mayor sea el valor del índice más atractivo será la cartera analizada ya que indicará un mayor retorno en relación al riesgo asumido.

Como lo afirman Rivas-Llosa, R., \& Camargo, G. (2002), el principal objetivo de cualquier gestión de inversiones es la búsqueda por obtener los niveles más altos de rentabilidad posibles con los niveles más bajos de volatilidad. Sin embargo, en el mercado los instrumentos financieros más rentables suelen ser también los más riesgosos debido a la gran incertidumbre de su comportamiento.

\subsection{Paradoja de Feldstein-Horioka}

Desde la teoría macroeconómica hasta los temas relacionados a finanzas internacionales, diversas investigaciones y teorías plantean la relación de la inversión y el ahorro. Un estudio que innovó este campo fue el realizado por Martin Feldstein y Charles Horioka (1980) que mediante una regresión de la tasa de inversión nacional sobre la tasa de ahorro nacional de series de tiempo de 21 países de la $\mathrm{OECD}^{3}$ que abarcaron el periodo 19601974 hallaron una correlación positiva y significativa entre ambas variables; es decir un $\alpha$ llamado "coeficiente de retención de ahorro" mayor a 0 y cercano a la unidad.

$$
\frac{\mathrm{I}_{\mathrm{i}}}{\mathrm{Y}_{\mathrm{i}}}=\mathrm{c}+\alpha \frac{\mathrm{S}_{\mathrm{i}}}{\mathrm{Y}_{\mathrm{i}}}+\varepsilon_{\mathrm{i}}
$$

Donde I es la inversión bruta doméstica, Y es el PBI nacional (Producto Bruto Interno) y S es el ahorro doméstico bruto del país i.

Este resultado causó conmoción entre los investigadores económicos ya que indicaba que la movilidad de capitales entre los países seleccionados era baja, lo que contradecía el pensamiento general de la época de que el ahorro generado por un país podía moverse libremente entre los países y buscar el retorno más atractivo invirtiendo en cualquier mercado del mundo al presentarse una reducción de los controles de capitales a partir de 1960 .

De esta manera Feldstein y Horioka deducen en su trabajo que el ahorro doméstico es determinante de la tasa de inversión al interior de una economía y que la mayor parte

${ }^{3}$ Organización para la Cooperación y el Desarrollo Económico (OECD en inglés) es un foro único en donde los gobiernos de las 34 economías democráticas más adineradas del mundo (sus integrantes generan cerca del $80 \%$ del PBI mundial) trabajan conjuntamente para enfrentar los desafíos económicos y sociales. 
de este ahorro no tiende a migrar hacia el exterior como inversión extranjera sino que permanece en el país de origen como inversión nacional.

La ecuación inicial de la paradoja ha sido extendida y modificada en otras investigaciones como las de Feldstein (1983), Bayomi (1990), Feldstein-Bacchetta (1991), Jansen y Schulze (1996), Blanchard y Fischer (1994), Pelagidis y Mastroyiannis (2003), Narayan (2005), entre otras para incorporar variables como el grado de apertura comercial, efectos demográficos, crecimiento poblacional, simulaciones de Monte Carlo, ciclos económicos y restricción presupuestaria intertemporal para muestras de diferentes países con la finalidad de obtener coeficientes más explicativos y se adaptan a diferentes contextos.

A modo de síntesis, los conceptos teóricos y conceptuales abordados en este capítulo procuran ayudar a la comprensión del tema analizado puesto que una vez identificadas las contribuciones académicas generales se puede dar paso a la aplicación de las mismas en realidades más específicas como la peruana. Esquematizando, la Teoría de portafolio, el índice de Sharpe y la paradoja de Feldstein-Horioka serán utilizados posteriormente en el tercer capítulo para comprobar las hipótesis planteadas, asimismo, la Teoría del ciclo de vida y la diversificación temporal se verán relacionadas con la existencia y justificación del régimen de los Multifondos peruano y demás temas empíricos focalizados en el plano local que aborda el siguiente capítulo. 


\section{CAPÍTULO II: SISTEMA PRIVADO DE PENSIONES EN EL PERÚ}

El siguiente capítulo tiene como finalidad analizar el Sistema Privado de Pensiones (SPP) peruano desde su creación hasta el año 2014, enfatizando el periodo de análisis seleccionado. Se inicia con una breve exposición de antecedentes en los que se explica el funcionamiento y los problemas que presentó el Sistema Nacional de Pensiones (SNP) antes de llegada de la administración privada, luego se da paso a una explicación detalladamente de las características y el desempeño del Sistema Privado de Pensiones (SPP) y la reforma de los Multifondos, para finalizar con un análisis de los fondos de pensiones con variables macroeconómicas de ahorro e inversión tanto privada como pública.

Para reforzar el análisis se utilizan tablas y figuras estadísticas, así como autores y estudios especializados sobre los sistemas pensionarios para la región latinoamericana y principalmente para el Perú. Es así como se pone en contexto la realidad nacional que instituye el panorama ideal para desarrollar en el último capítulo la evaluación del esquema de fondos múltiples en el SPP y el efecto sobre la inversión peruana.

\subsection{Regímenes de pensiones en el Perú}

A nivel mundial los primeros regímenes pensionarios definidos como esquemas de pagos rentas generalmente vitalicias a quienes se jubilan por edad o problemas de salud relacionados con discapacidad o invalidez tuvieron como beneficiados a los servidores públicos. Es por esto que la Ley General de Goces de 1850 promulgada por el gobierno del presidente Ramón Castilla, que estableció un régimen de jubilación para los servidores púbicos puede ser el referente del inicio de los esquemas pensionarios peruanos (Hidalgo, 2004)

Los regímenes de pensiones se dividen en dos grandes categorías: el sistema de reparto y el sistema de capitalización individual, ambos sistemas comparten la finalidad de brindar rentas para la jubilación; sin embargo, la modalidad con la que se financian estas prestaciones futuras es lo que las diferencia. En el caso peruano, el Sistema Nacional 
de Pensiones (SNP) ejemplifica la primera categoría y el Sistema Privado de Pensiones (SPP), la segunda.

\subsubsection{El Sistema Nacional de Pensiones}

La creación de este régimen pensionario se consolidó mediante el Decreto Ley 19990 del 24 de abrilde1973 durante el gobierno del General Juan Velasco Alvarado. El SNP unifica los regímenes anteriores la Caja Nacional del Seguro Social (Leyes 8433 y 13640), el Seguro Social del Empleado (Ley 13724) y el Fondo Especial de Jubilación de Empleados Particulares (FEJEP - Ley17262); su administración fue encargada al Instituto Peruano de Seguridad Social (IPSS) desde su creación en 1980 bajo el Decreto Ley23161 para ser reemplazado por la Oficina de Normalización Previsional (ONP) en $1995^{4}$.

Su funcionamiento se basa en un compromiso entre una generación y otra, en el cual el aporte de la población económicamente activa en el mercado laboral se usa para financiar las pensiones de las quienes que ya terminaron con su etapa laboral.

Inicialmente este sistema mostró resultados favorables, así como lo ilustra MesaLago (1985) hubo un incremento de 25\% entre 1972 y 1976 en la pensión real promedio pagada por el SNP; no obstante, el mismo autor luego manifiesta los problemas que comienzan a manifestarse en relación a la seguridad social al señalar que entre 1976 y 1982 estas pensiones reales caen en un 50\%.En los años siguientes esta tendencia decreciente continúa, tal como lo expone Boloña (1995) en su estudio al afirmar que de enero de 1987 a enero de 1989 pensiones mensuales caen de 60 dólares a 16 dólares, experimentando un descenso a una tercera parte tras el colapso del SNP bajo la administración del IPSS.

El desequilibrio económico y financiero que experimentó el IPSS se debió a diferentes razones, entre las que destacan el aumento del personal burocrático que pasó de 20 mil en 1980 a más de 41 mil en 1989 como consecuencia de la politización de la entidad, incremento de beneficios sin los aportes correspondientes al ampliar la cobertura en 4.5 millones de beneficiarios del seguro de salud a los familiares de los trabajadores sin aumentar el porcentaje del aporte y el incremento de la corrupción con sobreprecios

\footnotetext{
${ }^{4}$ La ONP fue creada en mayo de 1994 por la Ley 26323 y continúa siendo la institución encargada de la administración del SNP
} 
en la compra de insumos, pensionistas fantasmas, corrupción de revisores del IPSS a las empresas privadas, etc. (Boloña,1995, pp. 17-18)

Es así como se evidencia el manejo deficiente del SNP en el periodo administrado por el IPSS. En dicho periodo, según el Banco Mundial (1990) los gastos administrativos como porcentaje de los gastos totales se incrementaron de $14 \%$ a $21 \%$, el número de beneficiarios se triplicó, el ingreso real del instituto se redujo a la mitad y la pensión real promedio cayó en 77\%. Asimismo, entre 1981 y 1988 las inversiones de los fondos registraron rentabilidades del orden de $-37 \%$, finalmente la descapitalización del fondo se agudizo debido a la hiperinflación de fines de los 80 (Bernal, 2008, pág. 29)

Ante tal panorama, el Perú se encontraba en el último lugar en Latinoamérica, tal como se aprecia en la tabla 2.1, al presentar un rendimiento real de sus fondos al presentar un rendimiento de $-25 \%$ anual para el periodo 1981-1987 cuando la tasa de inflación promedio fue de 96\%, según las estimaciones de Mesa-Lago (1991)

Tabla 2.1

Rendimiento real promedio de los fondos de la seguridad social en cinco países latinoamericanos durante la década de 1980 (\%)

\begin{tabular}{|c|c|c|}
\hline País & Periodo & Rendimiento anual (\%) \\
\hline Chile & $1981-87$ & 13.8 \\
\hline Costa Rica & $1980-87$ & -10.5 \\
\hline Ecuador & $1980-86$ & -10.0 \\
\hline México & $1981-83$ & $-29-8$ \\
\hline Perú (*) & $\mathbf{1 9 8 1 - 8 7}$ & $\mathbf{- 2 5 . 0}$ \\
\hline & (*) Promedio simple de dos estimados (-20.6 y -29.4) \\
\hline
\end{tabular}

Fuente: Mesa-Lago (1991). Portafolio Performance of Selected Social Security Institutes in Latin America

En 1991, el SNP estaba al borde del colapso, un sistema financieramente insostenible en el que los aportes de aproximadamente 2 millones de trabajadores no bastaban para cubrir los beneficios otorgados a los 278 mil pensionistas. (Morón y Carranza, 2004, pág. 23). De igual forma, la proporción de trabajadores activos por 
trabajador pasivo en el SNP paso de 18 en 1980 a 7 en 1992, los sueldos reales sobre los que aportaba disminuyeron, el salario implícito promedio real de la base de aportaciones pasó de 1300 soles en 1980 a cerca de 400 soles en 1992 correspondientes a una disminución de las contribuciones totales al SNP en 57\% en términos reales (Montoro, 1994, p. 59)

Según la investigación de Rojas (2014), en el año 2012 la recaudación bruta fue solo de 2500 millones de nuevos soles, mientras que el monto total de pensiones entregadas fue de 4420 millones, lo cual arroja un déficit de casi 2000 millones según la $\mathrm{ONP}^{5}$.

Actualmente, el SNP sigue vigente tanto para pensionistas como para nuevas afiliaciones. La edad de jubilación es de 65 años, con 20 años de aportación como mínimo y la prestación se determina como porcentaje de la remuneración de referencia, calculada como el promedio de las 60 últimas remuneraciones (Dirección General de los Asuntos Económicos y Sociales, MEF, 2004, p. 2)

No obstante este régimen pensionario continúa activo en el mercado, aún requiere de transferencias gubernamentales para cumplir con sus obligaciones, tal y como lo afirma el Ministerio de Economía y Finanzas (MEF) que en su informe del 2004 concluye que el $85 \%$ de la pensión de una filiado promedio era cubierta con transferencia del Estado y que a pesar de los ajustes realizados al SNP, la situación deficitaria del sistema representa un importante gasto en pensiones y se estima seguirá aumentando en los próximos años dadas las previsiones de cambios demográficos en el futuro de un mayor envejecimiento poblacional; según estimaciones del MEF las transferencias de recursos del tesoro público a los regímenes públicos equivalían en el 2003 a 109\% de la inversión pública, $16 \%$ del presupuesto público y $3 \%$ del PBI a precios corrientes.

\subsubsection{La reforma de 1993: Creación del Sistema Privado de Pensiones}

El Sistema Privado de Pensiones peruano (SPP) fue creado en 1992 mediante el Decreto Ley $\mathrm{N}^{\circ} 25967$ como alternativa al sistema pensionario anterior e inició sus operaciones en junio de 1993, doce años después que Chile y fue el segundo país en adoptar este

\footnotetext{
5 Para más información ingresar a la siguiente página web: www.onp.gob.pe. - Información general, estadísticas ONP
} 
sistema en Latinoamérica, dicha Ley que corresponde al esquema de protección social a los trabajadores en materia de pensiones señala en su artículo primero que:

El SPP tiene como objeto contribuir al desarrollo y fortalecimiento del sistema de previsión social en el área de pensiones y está conformado por las Administradoras Privadas de Fondos de Pensiones (AFP), las que administran los Fondos de Pensiones y otorgan obligatoriamente a sus afiliados, las prestaciones de jubilación, invalidez, sobrevivencia y gastos de sepelio. (Ley No 25967, 1992, p. 3)

Las tendencias demográficas globales fueron uno de los primeros factores uno de los primeros factores que despertaron preocupación en relación a la sostenibilidad de los sistemas de pensiones en un mundo con poblaciones longevas y bajas tasas de fecundidad (Banco Mundial, 1994, p. 32). En los países en desarrollo, además, otros factores como las distorsiones del mercado laboral y las altas tasas de informalidad llevaron a cuestionarse la sostenibilidad de los sistemas de seguridad social de reparto (Kapsoli, 2007, p. 59)

Respondiendo a estos factores de alarma y la situación particular peruana de crisis, la creación del Sistema Privado de Pensiones se dio como respuesta al colapso que presentó el Sistema Nacional de Pensiones ante el cambio en la composición laboral y demográfica del país: El aumento de la expectativa de vida de los pobladores y la caída en el número de nuevos aportantes por el aumento de la informalidad y el desempleo afectaron el financiamiento de este sistema pensionario ya que la proporción de los aportes de los trabajadores dejaron de ser suficientes para cubrir las pensiones entregadas y fue el Estado el que comenzó a intervenir constantemente, creando desbalances fiscales.

A inicios de la década de los 90 el SNP se encontraba al borde del colapso financiera; como consecuencia de la hiperinflación y la distorsión de precios relativos, el valor real de sus activos había descendido notablemente. Al mismo tiempo, las obligaciones del sistema se habían expandido considerablemente debido a las políticas de ampliación de la cobertura del sistema adoptadas durante la década de los 80. En este contexto, el Gobierno del Presidente Fujimori decidió reformar el SNP, a través de un sistema de capitalización individual administrado por entidades privadas especializadas, similar al que se había credo en chile en la década de los 80. (Muñoz, 1999, p. 4)

Tal y como lo expone Muñoz (1999) la reestructuración al sistema de pensiones buscaba reemplazar el SNP por un sistema autofinanciado basado en los aportes individuales de cada trabajador. Con ello, los fondos previsionales pasarían a ser fondos 
intangibles fuera del manejo del Estado. Sin embargo, Morrón y Carranza (2004) explican que cuando fue creado el SPP y luego de negociaciones políticas con diversos sectores opositores a la reforma, la obligatoriedad de afiliación al SPP fue eliminada y se mantuvo el SNP como fuente de competencia al sistema.

\subsection{Evolución del Sistema Privado de Pensiones}

El interés principal del nuevo régimen pensionario fue el reestructurar completamente el sistema existente, a fin de que el fondo sea individual y autofinanciado por el propio trabajador mediante Cuentas Individuales de Capitalización para cada contribuyente.

En una coyuntura de eminente quiebra de los regímenes de pensiones bajo la administración del estado, la creación del Sistema Privado de Pensiones, buscó el establecimiento de un modelo previsional autofinanciado que asegure el bienestar de los trabajadores y sus familias, al momento de su jubilación o en caso de invalidez o fallecimiento. (Dirección General de los Asuntos Económicos y Sociales, MEF, 2004, p.

Apoyo Consultores (2010) expone que entre los objetivos de la creación del SPP tenemos el establecimiento de un sistema previsional sólido, la generación de flujos para el refuerzo y desarrollo del mercado de capitales, la intermediación del ahorro interno y la eliminación de la ineficiencia en el uso de recursos monetarios causado por el sistema de reparto del SNP; de tal manera que el nuevo régimen impacte en el bienestar de los afiliados, así como el de la economía peruana en general. De esta manera también se une al grupo de países en desarrollo que siguiendo las sugerencias del Banco Mundial y el Consenso de Washington ${ }^{6}$ dejan en mano del sector privado los sistemas previsionales; seguido posteriormente por Colombia, Uruguay, Argentina, Costa Rica y México en América Latina, y por Hungría y Polonia en Europa del Este.

Otro importante objetivo del nuevo régimen de pensiones es el de incrementar constantemente la cobertura a fin de que la mayor cantidad de personas puedan gozar de un ingreso cuando cesen sus actividades laborales por razones de invalidez o jubilación.

\footnotetext{
${ }^{6}$ Conjunto de políticas propuestas por ciertos economistas y un grupo de instituciones económicas ubicadas en Washington (Fondo Monetario Internacional, Banco Mundial y el Tesoro Americano) para promover el progreso económico en los países en desarrollo mediante privatizaciones, disciplina fiscal, liberalización comercial y desregulación (Stiglitz y Charlton, 2005, p. 2)
} 
Esta decisión de optar por un régimen de capitalización individual no solo ayudó a amortizar la insostenible situación por la que pasaba el SNP sino que también disminuyó las presiones fiscales que el anterior sistema imponía, tal y como Titelman (2008) resalta al exponer que la correlación entre las contribuciones de cada individuo y la pensión a la que accederían momento de su jubilación reduciría los requerimientos fiscales mediante el traspaso de los riesgos económicos y financieros de la provisión de las pensiones del estado a los trabajadores.

En el periodo de análisis escogido se observa que la cartera administrada por este sistema pensional ha crecido $87.55 \%$ y ha llegado a representar hasta $20.8 \%$ del Producto Bruto Interno (PBI). La disminución de los fondos en el 2008 es el resultado de la crisis internacional financiera que impactó fuertemente el mercado bursátil lo que originó que las rentabilidades del SPP fueran negativas la mayor parte del año; y en el 2011 la desaceleración del crecimiento de grandes economías como China en el plano mundial y el contexto fluctuante de la economía nacional por el panorama político electoral también repercutieron en el monto final de los fondos del sistema en ese año. Pese a estas situaciones, la tendencia global de la evolución de la cartera es creciente y estable.

Figura 2.1

Evolución de la Cartera Administrada por el SPP 2007-2014 (En millones de nuevos soles)

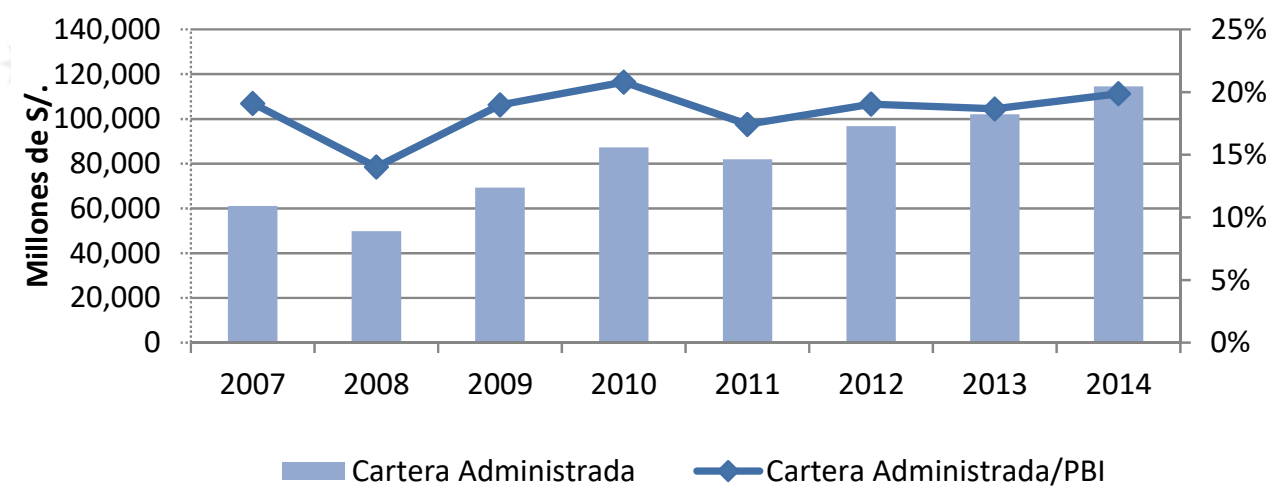

Fuente: Superintendencia de Banca, Seguros y Administradoras Privadas de Fondos de Pensiones (SBS), Banco Central de Reserva del Perú (BCRP) 


\subsubsection{Características}

Según Boloña (1995), las características más importantes del Sistema Privado de Pensiones peruano son: La libertad de elección cuando el afiliado tiene la posibilidad de cambiar de AFP, elegir la modalidad de jubilación y de retornar al SNP bajo las condiciones que establece el organismo regular; la propiedad de los fondos es exclusiva del afiliado con posibilidad de ser heredable e inembargable; las AFP deben seguir las reglas del mercado y las establecidas por el regulador al ser eficientes y rentables para no ser desplazadas del mercado; existe una relación directa entre el aporte y la futura pensión obtenida; y el afiliado puede controlar estrictamente su fondo mediante los estados de cuenta que recibe de su AFP y la información proporcionada por el organismo regulador.

Del mismo modo, Mendiola (2013) plantea otras características relevantes del sistema actual:

- $\quad$ El mercado de nuevos afiliados por aportes obligatorios crece a un ritmo aproximado del 5\% anual

- No hay diferencias significativas en los resultados de los fondos administrados por las AFP del mercado

- Los aportes obligatorios se calculan en base al 13\% de los conceptos remunerativos del empleado formal y son pagados por el empleador

- Las comisiones se cobran sobre el salario bruto del trabajador formal, lo que protege los ingresos de las AFP, aunque tengan pérdidas en los fondos de sus afiliados que administran

- Las AFP ofrecen prestaciones de jubilación, invalidez, sobrevivencia y gastos de sepelio a sus afiliados.

\subsubsection{Esquema de CIC}

Según el capítulo II de la Ley de SPP de la administración del fondo de pensiones, la Cuenta Individual de Capitalización (CIC) de aportes voluntarios es integrada por los aportes voluntarios del afiliado o de empleadores o terceros que efectúen aportes a favor del mismo. 
Cada CIC aumenta a partir de los aportes mensuales del afiliado y de las rentabilidades obtenidas sobre el fondo acumulado, los aportes pueden ser de carácter obligatorio o voluntarios, de esta manera es el mismo trabajador quien crea el fondo para su jubilación y el sistema se convierte sostenible en el tiempo.

Según la Superintendencia de Banca, Seguros y AFP (SBS), el aporte obligatorio está constituido por tres conceptos:

- $\quad$ El 10\% de la remuneración asegurable ${ }^{7}$

- Una prima de seguro, que le da derecho a recibir las prestaciones de invalidez, sobrevivencia y gastos de sepelio.

- Una comisión que debe pagar el afiliado a la AFP por administrar su CIC, la que es establecida por cada AFP y se calcula como un porcentaje de su remuneración máxima asegurable.

\subsubsection{AFP}

Las AFP son empresas privadas especializadas cuyo objetivo principal es la administración de los fondos de pensiones bajo la modalidad de Cuentas Individuales de Capitalización; asimismo se encargan de la recaudación de los aportes, tramitación de bonos de reconocimiento, y de mantener informados a sus afiliados y al organismo supervisor, la SBS, según los requerimientos que dicta la ley.

Otra de sus funciones es la de aumentar el valor esperado de las futuras pensiones que posteriormente entregarán a sus afiliados, al invertir adecuada mente en la mejor cartera de activos financieros según el tipo de fondo elegido por sus afiliados. El sistema peruano a la fecha cuenta con cuatro empresas administradoras: HABITAT, INTEGRA, PRIMA y PROFUTURO.

\footnotetext{
${ }^{7}$ Se considera remuneración asegurable al total de rentas provenientes del trabajo del afiliado percibidas en dinero, cualquiera sea la categoría de renta en la que se encuentren. Asimismo, se consideran afectos a los Aportes al SPP los subsidios temporales que por cualquier naturaleza reciba el afiliado, así como también las gratificaciones ordinarias que perciba. (https://www.sbs.gob.pe)
} 


\subsubsection{Supervisión y regulación}

Junto con el nacimiento del Sistema Privado de Pensiones y las AFP, se constituyó un organismo que en representación del Estado sea el encargado de supervisar y regular este nuevo mercado, este ente público fue la Superintendencia de AFP (SAFP). Posteriormente, en julio del 2000, se promulgó la Ley 27328, en virtud de la cual la SAFP es absorbida por la Superintendencia de Banca, Seguros y AFP (SBS) y asume las funciones relacionadas al SPP y las AFP.

Así, como lo explican Morón y Carranza (2003) la SBS es el organismo autónomo y especializado encargado del control del área financiera, actuarial, jurídica y administrativa de las empresas especializadas en el manejo de los fondos de pensiones del SPP.

Desde el punto de vista del regulador el diseño de los parámetros de inversión debe lograr un balance entre limitar la exposición al riesgo de las inversiones y reducir el impacto negativo de estas sobre la rentabilidad de las mismas. En el trade-off entre riesgo y rentabilidad esperada de una inversión el equilibro implica reducir el riesgo del portafolio sacrificando rentabilidad esperada, en este sentido, las regulaciones implican un costo al reducir las posibilidades de inversión. (Pereda, 2007, p. 4)

A través de esta institución, el Estado dicta normas para el buen funcionamiento del sistema y vela por el cumplimiento de las mismas. Todas las disposiciones regulatorias referentes al SPP se agrupan en el Texto Único Ordenado (TUO) de la Ley del Sistema Privado de Administración de Fondos de Pensiones (DS 054-97-EF) y su reglamento correspondiente (DS 004-98-EF) ${ }^{8}$. El TUO es un documento de 56 páginas que contiene siete títulos: (I) disposiciones generales y definiciones, (II) Formación de las AFP, (III) Aspectos societarios, (IV) Afiliación y aportes, (V) Gestión, (VI) Prestaciones, y (VII) Pensión mínima, régimen especial de jubilación anticipada en el SPP y jubilación adelantada del Decreto Ley N 19990 para afiliados al SPP.

Otro organismo público involucrado en la regulación del sistema es el Banco Central de Reserva el Perú (BCRP), al ser el encargado de fijar los límites ${ }^{9}$ a las inversiones que se realizan con los fondos del SPP en los diferentes tipos de instrumento

\footnotetext{
${ }^{8}$ Estos documentos, al igual que el Compendio de Normas Reglamentarias del SPP, pueden ser encontrados en la página web de la SBS: www.sbs.gob.pe

${ }^{9}$ Los límites se encuentran establecidos en el artículo 25-D de la Ley del SPP y el BCRP determina los porcentajes máximos operativos y/o sub-límites
} 
(ver anexo 1), tal como lo dictamina el décimo sexto artículo de las Disposiciones finales y transitorias del TUO.

Para proteger a los afiliados, toda AFP debe cumplir con la separación contable impuesta por el regulador al llevar un plan contable de los fondos de pensiones separado de la contabilidad de la empresa. Este mecanismo se basa en uno de los principios de la regulación financiera mencionados en la II Conferencia Internacional de Fondos de Pensiones (2001) por el Rodrigo Galarza, vicepresidente de Asofondos Colombia.

En setiembre del 2004, la SBS emitió dos resoluciones importantes; la primera con el objetivo de facilitar el traslado de los afiliados de una AFP a otra y la segunda para regular la reducción de comisiones de las AFP para aumentar la competencia entre las mismas $^{10}$.

La reforma más importante del SPP desde su creación se dio mediante la Ley $\mathrm{N}^{\circ}$ 29903 de julio de 2012 aprobada durante el Gobierno de Ollanta Humala, la cual introduce tres cambios novedosos al proponer un mecanismo explícito para reducir las comisiones cobradas por las AFP a sus afiliados, hacer obligatoria la afiliación a un sistema pensionario a trabajadores no mayores de 40 años independientes y de microempresas ${ }^{11}$, y la más relevante, cambiar el tipo de comisiones cobradas por las AFP de una comisión por flujo (porcentaje de las remuneraciones) a una comisión por saldo (porcentaje del valor del fondo individual).

\subsection{La reforma de 2005: Multifondos}

Durante doce años desde su creación, el SPP contaba solamente con un único tipo de fondo, este fondo estaba diseñado bajo condiciones de volatilidad y rendimiento moderado con una composición balanceada de renta variable y fija. Esta situación varía en el país cuando otras economías de la región comienzan a crear otros tipos de fondos para satisfacer mejor a los aportantes.

Es así como a partir de la promulgación de la Ley № 27988 en junio del 2003 en el Gobierno del Presidente Alejandro Toledo se introduce el esquema de fondos múltiples

\footnotetext{
${ }^{10}$ Véase resoluciones SBS 1582-2004 y 1583-2004 del 17 de setiembre de 2004.

${ }^{11}$ La obligatoriedad de los aportes independientes a las AFP fue derogada por el Congreso de la República el 29 de setiembre del 2014 luego de un debate tras una serie de protestas y críticas por parte de la población ante la norma
} 
con la finalidad que las AFP puedan ofrecer distintos tipos de fondos a sus aportes obligatorios, tomando en consideración el riesgo que cada afiliado desee asumir.

Los Multifondos entran en vigencia en diciembre del 2005 con el fin de ofrecer alternativas de inversión para los cotizantes ${ }^{12}$ de acuerdo a sus preferencias por el riesgo, con lo que se les otorga una participación más activa en la elección de su cartera de inversiones, dentro de los fondos ofrecidos. (Pereda, 2007, p.8).

Los afiliados al sistema pueden tener diversas preferencias relacionadas a la composición de la cartera de inversión de sus fondos de pensiones, que muestran los distintos grados de aversión al riesgo que estos poseen; la creación de un esquema de fondos múltiples permite abarcar mejor las preferencias de los afiliados.

\subsubsection{Clasificación de los fondos}

Este sistema cuenta con tres tipos de fondos, los cuales se diferencian por el riesgo de inversión que manejan y se dirigen a diferentes grupos etarios:

\section{- $\quad$ Fondo de Preservación de capital (Fondo Tipo 1)}

Apropiado para los afiliados mayores de 60 años, próximos a jubilarse o que perciben una pensión por la modalidad de retiro programado o renta temporal ya que al contar con un horizonte de inversión de corto plazo se les ofrece una alternativa de crecimiento estable y con bajo riesgo.

- $\quad$ Fondo Mixto (Fondo Tipo 2)

Está diseñado básicamente para los afiliados en edades intermedias, aproximadamente entre 45 y 60 años de edad pues ofrece un crecimiento moderado con riesgo medio, más acorde al grado de aversión al riesgo que estos afiliados poseen. Es el equivalente al Fondo Único previo a la introducción de los Multifondos.

\footnotetext{
${ }^{12}$ Afiliados que han registrado aportes a su Cuenta Individual de Capitalización en el mes, dichos aportes pueden corresponder a pagos oportunos o pagos de aportes devengados en meses anteriores.
} 
- $\quad$ Fondo de Apreciación de capital (Fondo Tipo 3)

Es el fondo más agresivo y tiene como finalidad buscar rendimiento a largo plazo por encima del promedio, pero está expuesto a un riesgo más alto, es por esto que está dirigido a los afiliados jóvenes cuyo horizonte de retiro es muy lejano y que pueden asumir los riesgos inherentes a las mayores fluctuaciones de las rentabilidades.

En el caso de que los afiliados no seleccionen un tipo de fondo, la asignación por parte de las Administradoras de Fondos de Pensiones (AFP) será de acuerdo a sus edades: Los menores de 60 años canalizarán sus aportes al Fondo Tipo 2, mientras que al sobrepasar ese rango de edad tendrán que ser asignados al Fondo Tipo 1 por estar próximos a jubilarse.

\subsubsection{Límites de inversión}

En el sistema de Multifondos se establece, al igual que en el sistema anterior de Fondo Único, la lista de instrumentos elegibles de inversión (encontrados en el Art. 25 del Texto Único Ordenado de la Ley del SPP - TUO), límites de inversión por emisor y grupo económico (con la excepción de los valores del Gobierno y del Banco Central) y límites máximos de inversión con fines de diversificación para ciertos instrumentos.

Cada tipo de fondo dispone de una estructura de inversión diferente en relación a los límites de inversión permitidos, los cuales se muestran en la tabla 2.2. Estos límites son establecidos por la SBS y con la autorización del Banco Central de Reserva del Perú (BCRP). 
Tabla 2.2

Límites máximos según Tipo de Fondo en el esquema Multifondos (\%)

\begin{tabular}{|c|c|c|c|c|c|c|}
\hline $\begin{array}{l}\text { Tipo de } \\
\text { Fondo }\end{array}$ & $\begin{array}{c}\text { Renta } \\
\text { Variable }^{13}\end{array}$ & $\begin{array}{l}\text { Renta } \\
\text { Fija }^{14}\end{array}$ & Derivados ${ }^{15}$ & $\begin{array}{c}\text { Certificados/Activos } \\
\text { en deposito }\end{array}$ & $\begin{array}{l}\text { Instrumentos } \\
\text { Alternativos }{ }^{17}\end{array}$ & $\begin{array}{l}\text { Instrumentos } \\
\text { extranjeros }\end{array}$ \\
\hline $\begin{array}{l}\text { Preservación } \\
\quad \text { (Tipo 1) }\end{array}$ & $10 \%$ & $100 \%$ & $10 \%$ & $40 \%$ & - & \multirow{3}{*}{$42 \%$} \\
\hline $\begin{array}{c}\text { Mixto } \\
\text { (Tipo 2) }\end{array}$ & $45 \%$ & $75 \%$ & $10 \%$ & $30 \%$ & $15 \%$ & \\
\hline $\begin{array}{l}\text { Crecimiento } \\
\text { (Tipo 3) }\end{array}$ & $80 \%$ & $70 \%$ & $20 \%$ & $30 \%$ & $20 \%$ & \\
\hline
\end{tabular}

Fuente: Texto Único Ordenado de la Ley del SPP - TUO (Artículo 25)

En el caso del límite máximo en inversiones en el extranjero, el BCRP lo ha venido aumentando para aumentar la cantidad de instrumentos en los que las AFP pueden invertir y beneficiar a los afiliados mediante rentabilidades potenciales mayores de sus fondos de pensiones.

Estas modificaciones tratan de responder ante las críticas de rigidez por parte de la regulción como la que expone Galarza (2001) al concluir quesii bien es cierto que el conjunto de parámetros dispuestos por la legislación vigente contribuyen al control de los riesgos asociados a la concentración sectorial, por emisor y emisión; la rigidez de dicha metodología crea sesgos que obstruyen la optimización de la gestión de los portafolio y pone obstáculos a la obtención de mayores tasas de capitalización a nieles adecuados de riesgos

\footnotetext{
${ }^{13}$ De retorno esperado parcial, no asegurado

${ }^{14}$ De retorno fijado desde el momento de su emisión o compra

${ }^{15}$ Productos/instrumentos financieros para cubrir posibles riesgos existentes

${ }^{16}$ Instrumentos de corto plazo de retorno fijo

${ }^{17}$ Instrumentos no tradicionales como activos reales, hedge funds, commodities, prívate equity, productos estructurados, entre otros.
} 


\subsubsection{Cobertura}

El Sistema Privado de Pensiones viene experimentando un importante crecimiento en función al volumen administrado y su relación con el PBI; esto debido a que cada año el número de afiliados, y por ende el monto de la cartera que el sistema administra, aumenta significativamente.

La cobertura o grado de penetración del SPP se mide a través del cálculo del número de afiliados con respecto a la PEA y constituye uno de los indicadores más importantes del éxito del establecimiento del sistema, teniendo en cuenta que uno de los objetivos fundamentales de un sistema previsional es de lograr que la mayor cantidad de la población posea un plan de pensiones. (Bernal, 2008, p. 13)

En el Perú el nivel de cobertura continúa siendo uno de los grandes desafíos del sistema ya que los ratios en función a la PEA no alcanzan aún ni el 50\%. Morrón y Carranza (2004) afirman en su estudio que el número de afiliados que cotizan en un año se ha mantenido alrededor del $54 \%$ por lo cual se diría que poco más de la mitad de afiliados tal vez no alcance una pensión de jubilación compatible con su historial de ingresos de su etapa laboral. Esta brecha entre afiliados y cotizantes parece mantenerse en todo el periodo analizado, tal como lo muestra la figura 2.2.

La cobertura del sistema es baja y el porcentaje de afiliados que cotizan es también reducido y presenta notoria diferencia entre las personas de distintos ingresos; esta desigualdad se evidencia en la investigación del Banco Mundial encabezada por Rofman (2005) al calcular que la cobertura de los empleados pertenecientes a los dos quintiles más ricos es 15 veces mayor a la de los dos quintiles más pobres. Uno de los factores que podría explicar esta restricción limitada a un grupo selecto de personas sería la existencia de un considerable sector informal en la economía peruana: Las empresas informales y sus trabajadores evaden las aportaciones obligatorias al sistema de pensiones; generando una relación inversa donde altos ratios de informalidad y evasión conllevan a bajos ratios de cobertura del sistema privado de pensiones. 
Figura 2.2

Ratios de Cobertura del SPP 2007-2014 (\%)

Afilidos/PEA Cotizantes/PEA

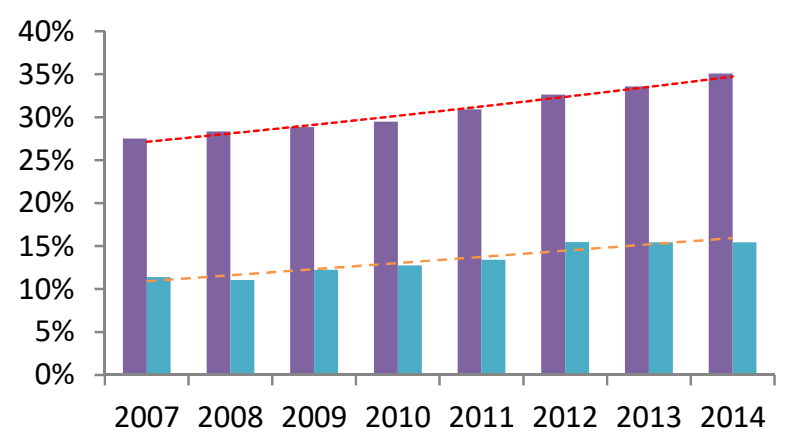

Fuente: Superintendencia de Banca, Seguros y Administradoras Privadas de Fondos de Pensiones (SBS), Instituto Nacional de Estadística e Informática (INEI)

\subsubsection{Desempeño de los fondos}

El desempeño de los fondos de pensiones está relacionado con la composición de la cartera administrada; al observar la tabla 2.3 se evidencia no solo la inversión que realizan las AFP respetando los límites que el regular impone sino también el impacto del aumento del límite en el exterior ya que la proporción de este tipo de inversiones ha aumentado de $13.19 \%$ en el 2007 al 35.19\% en el 2013. En las inversiones locales, la mayor proporción de los fondos se invierten en acciones de empresas no financieras y bonos del Gobierno Central. 
Tabla 2.3

Consolidado de la Cartera Administrada según Instrumento Financiero 2007-2013 (En millones de nuevos soles)

\begin{tabular}{|c|c|c|c|c|c|c|c|}
\hline Total SPP: FONDO TIP0 1,2 y 3 & 2007 & 2008 & 2009 & 2010 & 2011 & 2012 & 2013 \\
\hline L. INVERSIONES LOCALES & 52923 & 44085 & 54163 & 64343 & 58185 & 68055 & 66461 \\
\hline 1. Gobierno & 13394 & 12583 & 13917 & 14086 & 13915 & 16939 & 13746 \\
\hline Cerfficados y Depostos a Plazo del BCRP (1) & 790 & 448 & 365 & - & 886 & 2830 & 2191 \\
\hline Bonos del Gobierno Central & 12604 & 12134 & 13552 & 14086 & 13029 & 14109 & 11555 \\
\hline 2. Sistema Financiero & 8894 & 11611 & 11877 & 16528 & 14333 & 16268 & 22672 \\
\hline Cerificados y Depositos a Plazo (2) & 1463 & 4007 & 1777 & 5409 & 3656 & 3825 & 13151 \\
\hline $\begin{array}{l}\text { Titulos de Deuda enifidos por Organimos } \\
\text { Internacionales en elmercado local }\end{array}$ & 719 & 600 & 597 & 579 & 558 & 563 & 491 \\
\hline $\begin{array}{l}\text { Titulos de Deuda amifidos por Enfdades Financierss } \\
\text { del.Exterior en el mercado bcal }\end{array}$ & 956 & 1189 & 1069 & 764 & 504 & 436 & 403 \\
\hline Bonos de Amendamiento Financieno & 170 & 275 & 291 & 283 & 271 & 265 & 145 \\
\hline Bonos Subordnados & 774 & 795 & 1052 & 1401 & 1837 & 2385 & 2642 \\
\hline Otros Bonos Sedor Fnanciero & 740 & 1288 & 1224 & 1748 & 2204 & 3217 & 2904 \\
\hline Bonos Hipotecarios & 35 & 32 & 27 & 10 & 8 & 4 & 1 \\
\hline Aociones y Valores representativos sobre Acciones & 5027 & 3415 & 5840 & 6335 & 5294 & 5572 & 2934 \\
\hline Acciones Preferentes & 10 & 10 & - & - & - & - & . \\
\hline 3. Empresas no Financieras & 26389 & 16412 & 23892 & 27987 & 23175 & 26058 & 20207 \\
\hline Papeles Comenciales & 41 & 7 & 5 & - & 11 & - & . \\
\hline Pagares No Avalados LP & 217 & 198 & 215 & 171 & 171 & 141 & 130 \\
\hline $\begin{array}{l}\text { Titulos de Deuda emifdos por Enfdades No } \\
\text { Financierss del. Exderoren el mercado local }\end{array}$ & - & 846 & 911 & 997 & 768 & 845 & 1021 \\
\hline Bonos de Empresas no Funancierss & 5088 & 5329 & 6670 & 5182 & 5120 & 5544 & 4784 \\
\hline Bonos para Nuevos Proyecios & 921 & 822 & 250 & 244 & 224 & 256 & 307 \\
\hline Bonos Estructurados & - & 16 & 90 & 3 & - & - & . \\
\hline Aociones y Valores representativos sobre Acciones & 20122 & 9193 & 15752 & 21370 & 16881 & 19272 & 13965 \\
\hline 4. Administradoras de Fondos & 793 & 1603 & 1955 & 2701 & 3000 & 3680 & 4308 \\
\hline Cuotas de Fondos de Inversion & 793 & 1603 & 1815 & 2479 & 2615 & 3161 & 4082 \\
\hline Cuotas de Fondos Mutuos & - & - & 140 & 221 & 385 & 519 & 226 \\
\hline 5. Sociedades Titulizadoras & 2453 & 1876 & 2522 & 3061 & 3763 & 5111 & 5528 \\
\hline Bonos de Tituización & 2408 & 1839 & 2493 & 2997 & 3231 & 4269 & 4581 \\
\hline Bonos hipotecarios ftuizados & 45 & 37 & 29 & - & 43 & - & . \\
\hline Titulos con Derechode Participacion & - & - & - & 63 & 490 & 842 & 947 \\
\hline
\end{tabular}

\begin{tabular}{|c|c|c|c|c|c|c|c|}
\hline $\begin{array}{c}\text { Total SPP: FONDO } \\
\text { TIPO } 1,2 \text { y } 3 \\
\end{array}$ & 2007 & 2008 & 2009 & 2010 & 2011 & 2012 & 2013 \\
\hline $\begin{array}{l}\text { II. INVERSIONES EN } \\
\text { EL EXTERNOR }\end{array}$ & 8055 & 6192 & 14528 & 23001 & 23455 & 28512 & 35920 \\
\hline 1. Gobierno & 213 & 1162 & 849 & 2157 & 949 & 1705 & 1341 \\
\hline Titulos de Deuda & 213 & 1162 & 849 & 2157 & 949 & 1705 & 1341 \\
\hline 2. Sistema Financiero & 1216 & 1244 & 4053 & 3523 & 2756 & 2640 & 2732 \\
\hline $\begin{array}{l}\text { Bonos del Sistema } \\
\text { Financiero } \\
\text { Titulos de Deuda }\end{array}$ & 652 & 422 & 675 & 1104 & 1094 & 2154 & 1694 \\
\hline $\begin{array}{l}\text { Emifdos por } \\
\text { Organismo } \\
\text { Internacional } \\
\text { Certicados } y\end{array}$ & - & 16 & - & - & - & - & - \\
\hline $\begin{array}{l}\text { Depósitos a Ṕlazo (1) } \\
\text { (4) }\end{array}$ & 370 & 408 & 747 & 887 & 621 & 308 & 410 \\
\hline $\begin{array}{l}\text { Aociones y Valores } \\
\text { representatvos sobre } \\
\text { Aociones }\end{array}$ & 143 & 399 & 2631 & 1533 & 1041 & 178 & 628 \\
\hline Aociones preferentes & 51 & - & - & - & - & - & - \\
\hline $\begin{array}{l}\text { 3. Empresas no } \\
\text { Financieras }\end{array}$ & 138 & 423 & 5572 & 10794 & 8220 & 6249 & 6752 \\
\hline Bonos Coporativos & 36 & 91 & 908 & 2819 & 2814 & 2447 & 2202 \\
\hline $\begin{array}{l}\text { Aociones y Valores } \\
\text { representativos sobre } \\
\text { Aociones }\end{array}$ & 102 & 332 & 4664 & 7975 & 5407 & 3802 & 4550 \\
\hline $\begin{array}{l}\text { 4. Administradoras } \\
\text { de Fondos }\end{array}$ & 6488 & 3362 & 4053 & 6478 & 11529 & 17918 & 25095 \\
\hline $\begin{array}{l}\text { Cuotas de Fondos } \\
\text { Mutuos (5) }\end{array}$ & 6337 & 3207 & 4053 & 6478 & 11529 & 17918 & 25095 \\
\hline $\begin{array}{l}\text { Cuotas de Fondos de } \\
\text { Inversión }\end{array}$ & 151 & 156 & - & - & - & - & - \\
\hline $\begin{array}{l}\text { 5. Sociedades } \\
\text { Titulizadoras }\end{array}$ & - & - & - & 50 & - & 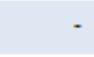 & - \\
\hline Bonos de Tituizacion & - & - & - & 50 & - & - & - \\
\hline $\begin{array}{l}\text { III. OPERACIONES } \\
\text { EN TRANSITO }\end{array}$ & 73 & -396 & 597 & -49 & 260 & 286 & -304 \\
\hline TOTAL & 61051 & 49881 & 69287 & 87296 & 81900 & 96853 & 102077 \\
\hline Fondo de Pensiones & 60406 & 49380 & 68595 & 86391 & 81052 & 95907 & 101113 \\
\hline Encaje Legal & 645 & 501 & 692 & 904 & 848 & 946 & 964 \\
\hline
\end{tabular}

Fuente:Fuente: Superintendencia de Banca, Seguros y Administradoras Privadas de Fondos de Pensiones (SBS) 
Las bajas y fluctuantes rentabilidades obtenidas por las AFP en el inicio de la implementación de los Multifondos se explican por las restricciones de inversión en el exterior. Esto se debe a la ausencia de una asignación optima de la cartera aunado a las condiciones particulares del mercado de capitales peruano, entre las que destaca la escasa liquidez del mercado secundario la cual resta flexibilidad en el manejo y afecta el desempeño de las inversiones (Revista Economía y Sociedad, 2003, número 50, p. 1528)

Para el periodo 1995-2004, Pereda (2007) muestra que los fondos de pensiones habrían tenido una rentabilidad potencial menor en aproximadamente $2.5 \%$ promedio anual, de los cuales los límites de inversión explicarían el 1.9\% debido al efecto de estos en la capacidad de las AFP de elegir las mejores alternativas de inversión disponibles.

La administración efectuada por las AFP explicaría el 0.6\% restante; no obstante, se muestra además que los efectos negativos de las regulaciones se redujeron en el periodo 2003-2004 debido a una mayor disponibilidad de instrumentos de inversión, un entorno macroeconómico más estable y las ganancias del aprendizaje en el manejo de los fondos. Finalmente, el estudio concluye que las AFP tienen una marcada preferencia por invertir en portafolios de mayor riesgo dependiendo de lo que las regulaciones les permiten.

La introducción de los Multifondos en el mercado peruano coincidió con una época de crecimiento y optimismo general en la economía, lo que reflejo los altos rendimientos logrados en 2006 y 2007 pero que luego se vieron revertidos negativamente cuando la volatilidad de precios internaciones de los minerales afectaron la bolsa local y a los fondos de pensiones.

Una vez pasada la crisis financiera el mercado bursátil internacional y peruano se empezó a recuperar lo cual favoreció las rentabilidades de todos los fondos; sin embargo, en los últimos años del periodo de análisis se observa una desaceleración en el crecimiento porcentual de estas rentabilidades. 
Figura 2.3

Rentabilidad Nominal por Tipo de Fondo 2007-2014 (\%)

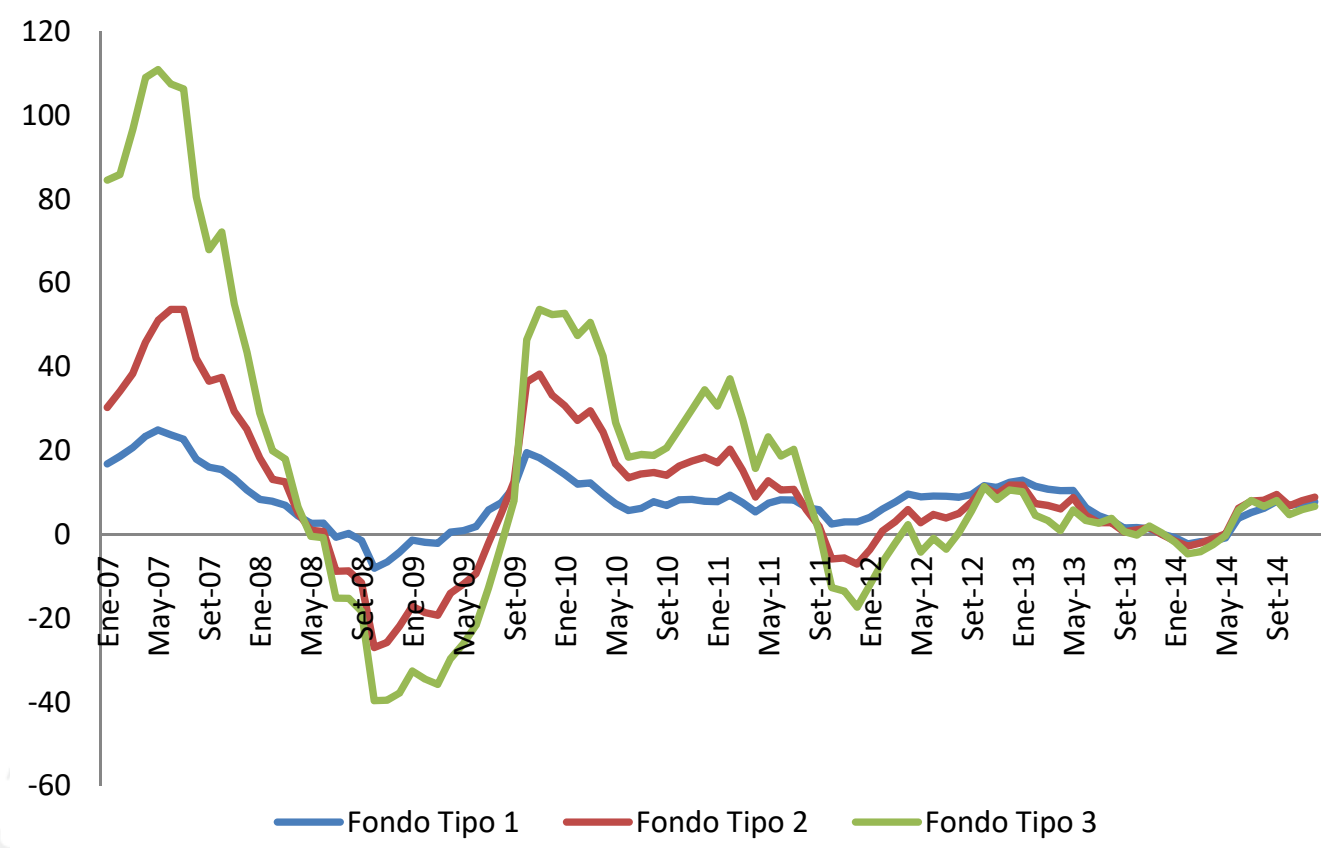

Fuente: Superintendencia de Banca, Seguros y Administradoras Privadas de Fondos de Pensiones (SBS)

Lo que la figura 2.3 pone en evidencia es que el Fondo Tipo 3 es el que presenta mayores rentabilidades durante todo el periodo pero tambien las mayores péridas en el periodo de crisis financiera, esto se debe a la mayor proporción de renta variablle que posee. El Fondo Tipo 1 presentó fluctuaciones estables durante el periodo generando así una rentabilidad acumulada positiva que cumple con la función asignada de presenvación de capital.

El Fondo Tipo 2 siguió las mismas tendencias que el Fondo Tipo 3 pero con una menor relación de rentabilidad/périda y al ser el Fondo con mayor cantidad de afiliados (como se muestra en la tabla 2.4) es el que impacta en mayor escala al resultado de la cartera administrada total del SPP. 
Tabla 2.4

Distribución de Afiliados por Tipo de Fondo y por Rango de Edad

\begin{tabular}{|c|c|c|c|c|}
\hline & \multicolumn{3}{|c|}{ Tipo de Fondo } & \multirow{2}{*}{ Total } \\
\hline & Fondo Tipo 1 & Fondo Tipo 2 & Fondo Tipo 3 & \\
\hline Total SPP & 263,124 & $5,172,446$ & 294,039 & $5,729,609$ \\
\hline 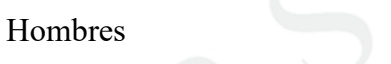 & 195,446 & $3,215,859$ & 199,528 & $3,610,833$ \\
\hline Mujeres & 67,678 & $1,956,587$ & 94,511 & $2,118,776$ \\
\hline \multirow[t]{3}{*}{ Distrib. Por Tipo de Fondo } & $4.59 \%$ & $90.28 \%$ & $5.13 \%$ & $100 \%$ \\
\hline & & Rango de Edad & & \multirow{2}{*}{ Total } \\
\hline & $56-65<$ & $41-55$ & $<21-40$ & \\
\hline Total SPP & 491,499 & $1,784,828$ & $3,453,282$ & $5,729,609$ \\
\hline Distrib. Por Rango de Edad & $8.58 \%$ & $31.15 \%$ & $60.27 \%$ & $100 \%$ \\
\hline
\end{tabular}

Fuente: Superintendencia de Banca, Seguros y Administradoras Privadas de Fondos de Pensiones (SBS)

Una observación interesante que se puede inferir de las tablas anteriores es que la reforma de los Multifondos aún no es muy utilizada entre los afiliados del SPP ya que mas del $90 \%$ se concentra en el Fondo Tipo $2^{18}$. Esta situación se puede deber a diversos factores, entre los cuales está la afiliación inmediata según ley al Fondo Tipo 2 (Fondo Mixto) cuando el trabajador ingresa al SPP, situación que permanece inalterada hasta que la AFP traslade al afiliado al fondo de su elección mediante una solicitud de cambio o elección de fondo de pensiones a la AFP respectiva; este cambio no se realiza con frecuencia debido al desinterés del usuario y/o a la desinformación de la capacidad de los afiliados a cambiarse de tipo de fondo las veces que lo requieran (ver anexo 2).

${ }^{18}$ Fondo de pensiones que se instauró desde la creacion de todo el sistema bajo administración del sector
privado en 1992 
De este mismo modo, otra observación es la desconexión entre la distribución por rango de edad y la distribución por tipo de fondo, en este caso la población no esta aprovechando los tipos de fondos disponibles según la etapa en el ciclo laboral en el que se encuentra; es decir, no está haciendo uso de la diversificación temporal al no seleccionar su tipo de fondo según su capacidad de aversión al riesgo ${ }^{19}$

\subsection{Efectos macroeconómicos del SPP}

Las reformas al Sistema Peruano de Pensiones han producido diversos efectos macroeconómicos a la economía nacional, entre las principales variables económicas afectadas tenemos al ahorro e inversión privadas.

\subsubsection{Vinculación con el ahorro nacional}

El traslado de recursos de los trabajadores a sus AFP es en el largo plazo es devuelto en forma de pensiones, lo cual genera un incremento importante en el ahorro nacional (Boloña, 1995, p. 86)

Del mismo modo, autores como Orszag y Stiglitz (2001) exponen su punto de vista sobre la relación positiva que existe entre ambas variables con el concepto de prefinanciamiento (prefunding) al afirmar que: "En un sentido limitado, prefinanciamiento significa que el sistema de pensiones está acumulando activos (suficientes) para satisfacer futuros pagos. En un sentido amplio; sin embargo, prefinanciamiento significa aumentar el ahorro nacional” (p. 21)

La Federación Internacional de Administradoras de Fondos de Pensiones (2003) expone que la reforma de pensiones puede afectar el ahorro nacional mediante cuatro canales:

- El cambio en el superávit global del Gobierno, considerando la magnitud del déficit pensional de transición causando por la reforma y la respuesta fiscal a dicho déficit, reflejada en el déficit no pensional

- El nuevo ahorro pensional obligatorio de los hogares impuesto por la reforma

\footnotetext{
${ }^{19}$ Según la diversificación temporal, las personas más jóvenes y en los inicios de su vida laboral son menos adversos al riesgo, eligiendo portafolios con mayores rentabilidades potenciales al poder asumir mayores riesgos.
} 
- La respuesta del ahorro privado al cambio en el ahorro total del gobierno

- La respuesta del ahorro voluntario de los hogares al ahorro pensional obligatorio que deben realizar

En el caso peruano, se cumple con las afirmaciones anteriores de una relación estrecha entre el nivel de ahorro y el sistema de pensiones ya que como se observa en la figura posterior ambas variables siguen una misma tendencia. De esta manera se observa que las fluctuaciones del SPP tienen un impacto en el ahorro interno peruano tanto público (al relacionarse con el déficit fiscal y las transferencias del gobierno) como privado (alterando el nivel de ahorro voluntario y forzoso).

Figura 2.4

Relación entre el Ahorro y el SPP ${ }^{20}, 2007-2014$ (Millones de nuevos soles)

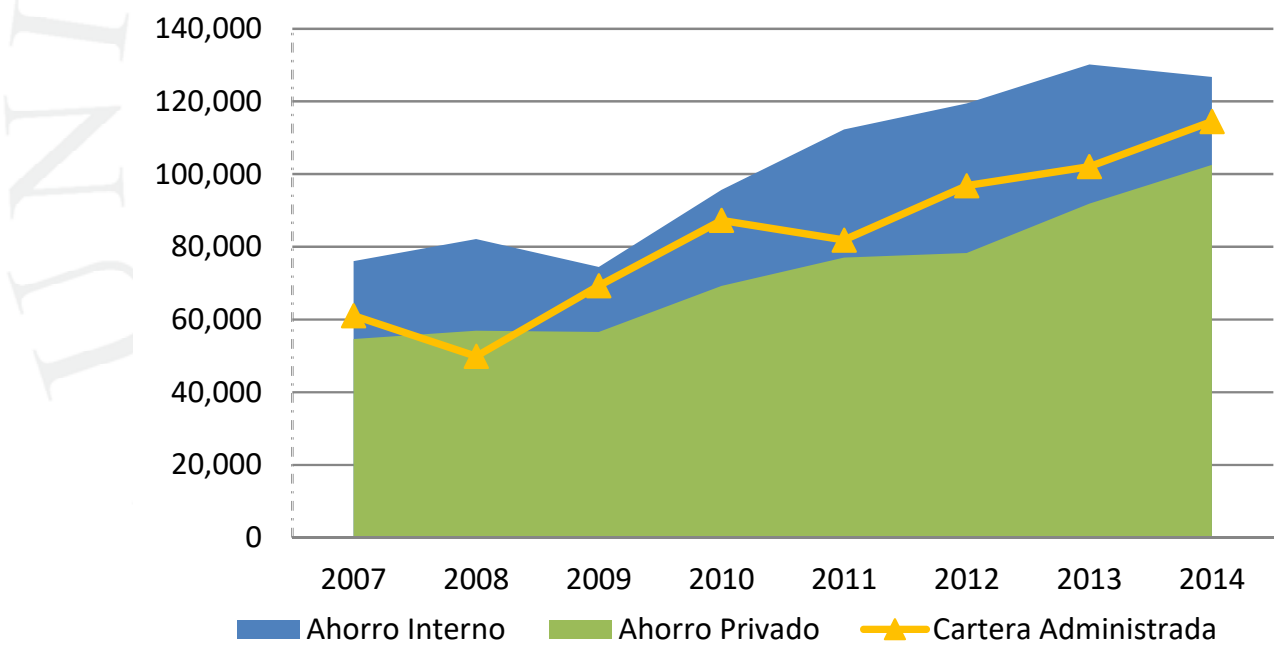

Fuente: Superintendencia de Banca, Seguros y Administradoras Privadas de Fondos de Pensiones (SBS), Banco Central de Reserva del Perú (BCRP)

\subsubsection{Vinculación con la inversión nacional}

Existe amplia evidencia internacional de que la tasa de ahorro nacional está correlacionada con la tasa de inversión nacional, desde el estudio para los países de la OECD de Feldstein y Horioka (1980) hasta el de Calderón y Schmidt-Hebbel (2003) para

\footnotetext{
${ }^{20} \mathrm{El}$ valor calculado para el nivel de ahorro interno y privado del 2014 corresponden a los datos del tercer trimestre del año
} 
una muestra mundial. En base a la relación explicita hallada por las investigaciones antes mencionadas entre la inversión y el ahorro, también es posible afirmar que los fondos de pensiones impactan en la inversión nacional. Esto ocurre cuando el ahorro adicional obtenido por la influencia del SPP es invertido en la economía nacional ya sea en el sector público o privado.

Siguiendo esta línea de pensamiento la figura 2.5 refleja que la inversión y la cartera administrada por el SPP presentan una correlación; no obstante, este impacto no es inmediato ya que los movimientos en la cartera parecen reflejarse en el periodo siguiente en la inversión.

Figura 2.5

Relación entre la Inversión y el SPP²1, 2007-2014 (Millones de nuevos soles)

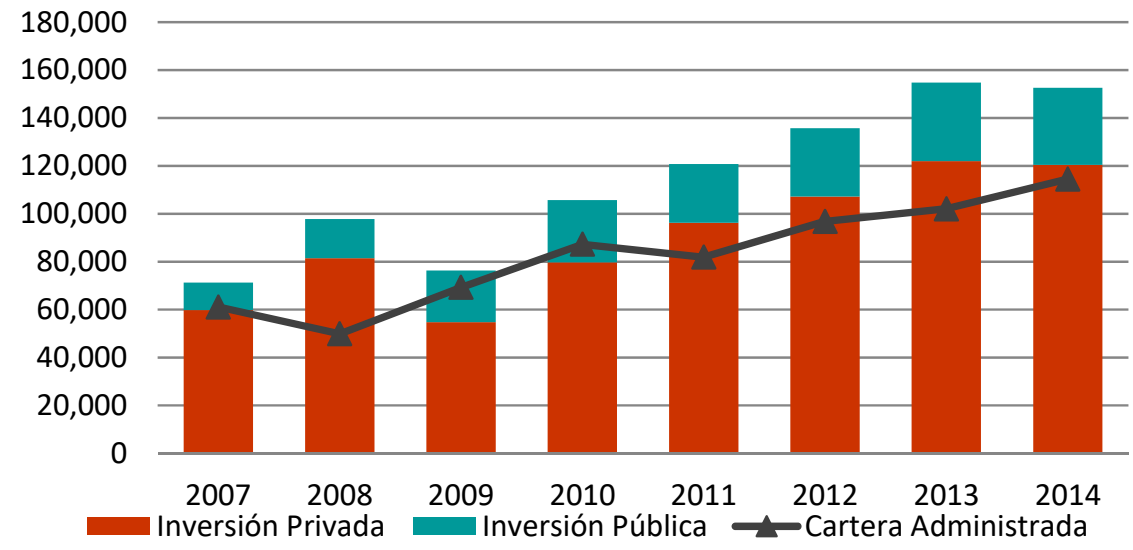

Fuente: Superintendencia de Banca, Seguros y Administradoras Privadas de Fondos de Pensiones (SBS), Banco Central de Reserva del Perú (BCRP)

Es así que luego de analizar el Sistema Privado de Pensiones desde su creación hasta el año 2014 se puede concluir que, si bien aún posee desafíos pendientes, ha solucionado algunos de los problemas del sistema anterior como las presiones fiscales, la menor cobertura, el bajo monto pensional, entre otros; siendo de gran beneficio para sus afiliados al invertir los aportes obligatorios que recogen e incrementar los fondos que luego serán devueltos a los usuarios como pensiones de jubilación.

${ }^{21}$ El valor calculado para el nivel de inversión interna y privada del 2014 corresponden a los datos del tercer trimestre del año 
Sin embargo, la última reforma de los Multifondos implementada con el objetivo de seguir incrementando el bienestar futuro de la población no parece ser tan utilizada por los afiliados; en este sentido la presente investigación pretende cuantificar el impacto del uso de estos fondos múltiples en el SPP y su relación en el incremento de las rentabilidades de estos fondos, el ahorro y la inversión nacional, a fin de demostrar el beneficio potencial de esta reforma en la economía en general y fomentar el uso activos de la misma. 


\section{CAPÍTULO III: EL EFECTO DE LOS MULTIFONDOS EN EL SISTEMA PRIVADOR DE PENSIONES Y LA INVERSIÓN PERUANA}

A lo largo de este capítulo se desarrollará las metodologías seleccionadas para poder alcanzar los objetivos planteados y comprobar las hipótesis sobre la existencia de efectos positivos de la reforma de Multifondos en el Sistema Privado de Pensiones y en la inversión total doméstica. De acuerdo a la disponibilidad de información diferenciada para los tres tipos de fondos que ofrece la reforma se consideró adecuado utilizar como periodo de análisis los años 2007-2014.

En la primera sección del capítulo se mostrarán las variables a ser utilizados en las pruebas, las cuales han sido obtenidas de la Superintendencia de Banca, Seguros y AFP (SBS), del Banco Central de Reserva del Perú (BCRP) y de Bloomberg. Asimismo, se explicará la metodología que se va a aplicar en cada caso, para finalmente presentar los resultados encontrados y brindar la interpretación económica adecuada.

\subsection{Elección de variables}

Todas las variables escogidas para la elaboración del presente documento se detallan en la tabla 3.1 donde se especifica la periodicidad y la fuente donde se obtuvo cada una de ellas, es preciso resaltar que los datos recolectados corresponden únicamente al periodo 2007-201422 y que las fuentes seleccionadas son entidades confiables que brindan datos estandarizados y comparables.

${ }^{22}$ El periodo de análisis inicia en el 2007 porque es a partir de este año que la Superintendencia de Banca, Seguros y AFP dispone de datos para los tres tipos de fondos que conforman el nuevo esquema de Multifondos 
Tabla 3.1

Descripción de variables utilizadas para el análisis

\begin{tabular}{|l|l|l|}
\hline \multicolumn{1}{|c|}{ Nombre } & \multicolumn{1}{|c|}{ Periodicidad } \\
\hline Rentabilidad Real Fondo Tipo 1 & Mensual & SBS Estadísticas del SPP \\
\hline Rentabilidad Real Fondo Tipo 2 & Mensual & SBS Estadísticas del SPP \\
\hline Rentabilidad Real Fondo Tipo 3 & Mensual & SBS Estadísticas del SPP \\
\hline $\begin{array}{l}\text { Índice General de la Bolsa de Valores de } \\
\text { Lima (IGBVL) }\end{array}$ & Mensual & Bloomberg \\
\hline Inversión Total (\% del PBI) & Trimestral & BCRP Series Estadísticas \\
\hline Ahorro Público (\% del PBI) & Trimestral & BCRP Series Estadísticas \\
\hline Cartera Administrada del SPP & Trimestral & SBS Estadísticas del SPP \\
\hline
\end{tabular}

Elaboración Propia

\subsection{Metodología}

Teniendo en cuenta los conceptos desarrollados en el primer capítulo se han seleccionado dos metodologías diferentes para la comprobación de las hipótesis: El índice de Sharpe para calcular el efecto de los Multifondos en el Sistema Privado de Pensiones y la paradoja de Feldstein-Horioka para calcular el efecto sobre la inversión peruana. Se utilizarán para ello, el programa Microsoft Excel y el programa econométrico Stata10, respectivamente.

\subsubsection{Efecto sobre el Sistema Privado de Pensiones}

La primera hipótesis específica de la investigación se relaciona con la idea de que el esquema Multifondos presenta un impacto positivo en el Sistema Privado de Pensiones al ofrecer una gama de tres fondos utilizables durante el periodo de aportes.

\footnotetext{
${ }^{23}$ En la página web de la Superintendencia de Banca, Seguros y AFP la información se encuentra en periodicidad mensual, pero para el presente trabajo se utilizó un promedio simple para convertirla en trimestral
} 
Para cuantificar el impacto de esta reforma se construirá dos escenarios para el mismo periodo de análisis y se comparará el desempeño de los aportes realizados en ambos escenarios. El primer escenario no tomará en cuenta los fondos múltiples ya que solo se construirá utilizando las rentabilidades reales del Fondo Tipo 2 (el cual representa el único fondo que existe desde la creación del SPP); en cambio, el segundo escenario es el que considera el esquema de los Multifondos al abarcar los tres fondos existentes durante todo el periodo analizado, como se muestra en la figura 3.1; la elección de la distribución de los tipos de fondos en el periodo analizado del segundo escenario se basa en las recomendaciones de la SBS según la edad ${ }^{24}$ :

- Fondo Tipo 1, diseñado para afiliados mayores de 60 años

- Fondo Tipo 2, dirigido básicamente para afiliados entre 45 y 60 años

- Fondo Tipo 3, adecuado para los afiliados más jóvenes del sistema

Figura 3.1

Escenarios planteados para el análisis

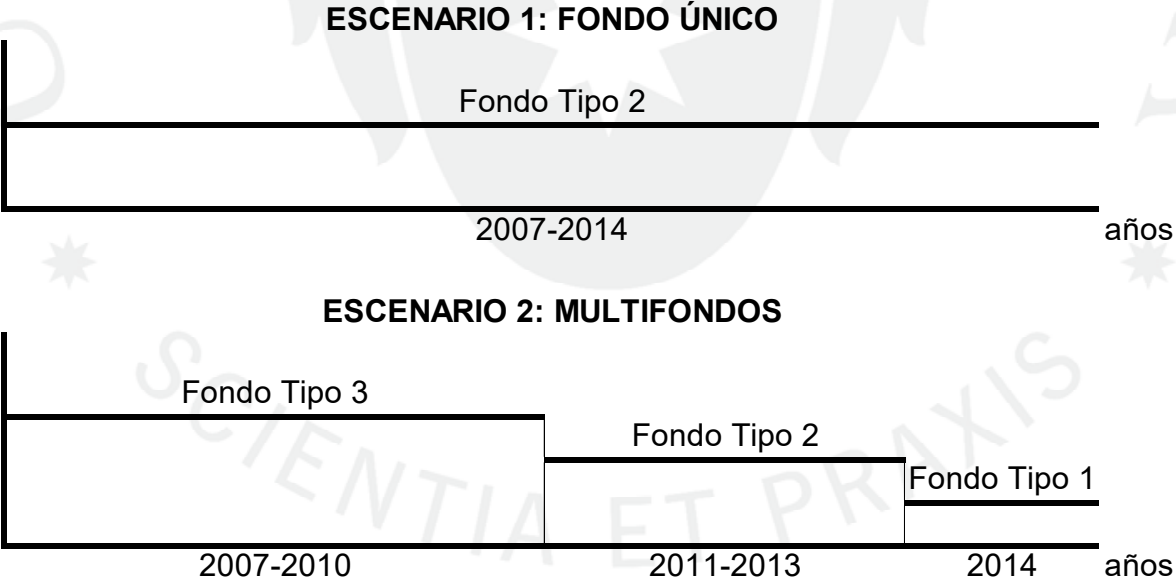

Elaboración propia

${ }^{24}$ Como el periodo escogido (2007-2014) es un periodo proxy al total de un afiliado se debe utilizar los fondos disponibles en una proporción similar al que se utilizaría en un tiempo de aportes real. 
Para evaluar el desempeño de cada escenario se hará uso del Índice de Sharpe, el cual es considerado un indicador de desempeño que calcula el rendimiento por unidad de riesgo en un portafolio:

$$
S_{p}=\frac{E_{p}-R_{f}}{\sigma_{p}}
$$

El principio que justifica la utilización del Índice de Sharpe se basa en el desarrollo de William Sharpe (1966) para la evaluación de Fondos Mutuos, donde propuso identificar la eficiencia relativa de estos activos a través de este índice, el cual es la pendiente de la frontera de posibilidades de inversión ${ }^{25}$, donde la mejor alternativa fue la que tenía la pendiente más elevada; es decir, la de mayor índice.

Asimismo, el trabajo de Zurita y Jara (1999) concluyó que este indicador tiene ventajas como medida de desempeño ajustada por riesgo para los fondos de pensiones porque:

- Supone que los fondos de la cartera administrada por las AFP representan gran parte de la riqueza de los cotizantes al jubilar, lo que parece apropiado para la mayoría de los pensionados a la fecha de jubilación

- Ocupa el concepto de riesgo total que es el más apropiado para fondos de pensiones

- No depende de un modelo específico de valoración de activos

- No requiere identificar el porfolio de mercado ya que en particular no se basa en el modelo del CAPM ${ }^{26}$

Es así como a partir de estas investigaciones la mayoría de análisis sobre los sistemas pensionarios y AFP en diversos países usan el índice de Sharpe para calcular y comparar el desempeño de los fondos.

En el presente estudio se tomará el rendimiento mensual como retorno, la desviación estándar mensual como riesgo y la tasa del bono soberano peruano en soles como tasa libre de riesgo.

\footnotetext{
${ }^{25}$ Si bien fue Sharpe quien desarrollo la idea de evaluar los activos desde esta perspectiva, en estricto rigor, fue Tobin (1958) quien elaboró el concepto de la frontera de posibilidades de inversión

${ }^{26}$ El Capital Asset Pricing Model (CAPM) es un modelo de valoración de activos financieros
} 


\subsubsection{Efecto sobre la inversión peruana}

La segunda hipótesis específica de este estudio se centra en la idea de que las carteras administradas por el sistema pensionario, regidos por el esquema de fondos múltiples desde el 2005 y consideradas como ahorro obligatorio por parte de los trabajadores, presentan una correlación positiva con la inversión peruana durante el periodo 20072014.

La metodología para la contrastación de esta hipótesis se basa en el trabajo de Vittorio Corbo y Klaus Schmidt-Hebbel (2003) ${ }^{27}$ que investiga los efectos sobre la inversión doméstica de la reforma de pensiones en Chile ${ }^{28}$; estos autores estiman una simple ecuación que toma la especificación de la paradoja de Feldstein-Horioka:

$$
\frac{\text { Inversión }}{P B I}=\alpha_{0}+\alpha_{1} \frac{\text { Ahorro }}{P B I}
$$

En la ecuación el componente de la reforma pensionaria se incluye en la variable Ahorro/PBI puesto que al plantear un aporte mensual obligatorio este fondo de pensiones se traduce en un ahorro forzoso que forma parte del ahorro privado. El coeficiente de interés para medir el efecto planteado es el $\alpha_{1}$, el cual se espera sea un valor significativo positivo y mayor a cero para establecer una relación directa entre ambas variables.

Para una mejor especificación de la ecuación se ha dividido el componente del ahorro nacional en: Cartera administrada por el SPP y ahorro público; puesto que es necesario tener representada en la variable ahorro componentes privados y públicos para poder compararla con la variable de inversión total nacional. Con estas especificaciones la ecuación final es la siguiente:

$$
\frac{\text { Inversión Total }}{P B I}=\alpha_{0}+\alpha_{1} \frac{\text { Cartera Adm.SPP }}{P B I}+\alpha_{2} \frac{\text { Ahorro Publico }}{P B I}
$$

\footnotetext{
${ }^{27}$ Ambos doctores en economía del M.I.T (Massachusetts Institute of Technology). Esta investigación es parte de la amplia evidencia internacional de la correlación entre las tasas de ahorro nacional e inversión nacional desde el clásico estudio de Feldstein y Horioka en 1980 para los países de la OECD.

28 El documento en mención forma parte del Seminario Internacional "Resultados y Desafíos de las Reformas a las Pensiones" organizado por la Federación Internacional de Administradoras de Fondos de Pensiones (FIAP) en mayo del 2003 en la ciudad de México.
} 


\subsection{Presentación de los resultados}

Una vez realizadas cada una de las técnicas mencionadas en la sección anterior, a continuación, se exhiben los resultados obtenidos y se interpretan a fin de dar respaldo o no a las hipótesis planteadas.

\subsubsection{Comparación de escenarios planteados}

Como se explicó anteriormente, para analizar el efecto de la reforma Multifondos sobre el SPP fue necesaria la construcción de dos escenarios utilizando las rentabilidades nominales del sistema de pensiones brindadas por el organismo supervisor, la SBS.

Como se observa en la figura 3.2 el Escenario "Multifondos", el cual se hace uso de los tres fondos múltiples que ofrece el sistema y será nombrado escenario 2 a partir de este momento, presenta diferencias marcadas en rentabilidad y pérdidas en el primer tramo del periodo que comprende los años 2007-2010sobre el escenario "Fondo Único", el cual solo se considera el fondo conservador que ha existido desde la creación del SPP y será nombrado solo escenario 1 de ahora en adelante; esto se debe al uso del Fondo Tipo 3 (el más agresivo) en el escenario Multifondos ya que al estar compuesto principalmente de renta variable es más volátil y premia la mayor exposición al riesgo con retorno adicional.

La pregunta clave que se infiere de la figura y que es uno de los temas centrales del presente trabajo es si verdaderamente el escenario más volátil tiene un mejor desempeño al finalizar el periodo de análisis al brindar una mayor rentabilidad por el riesgo asumido. 
Figura 3.2

Rentabilidad mensual de cada escenario, 2007-2014 (\%)

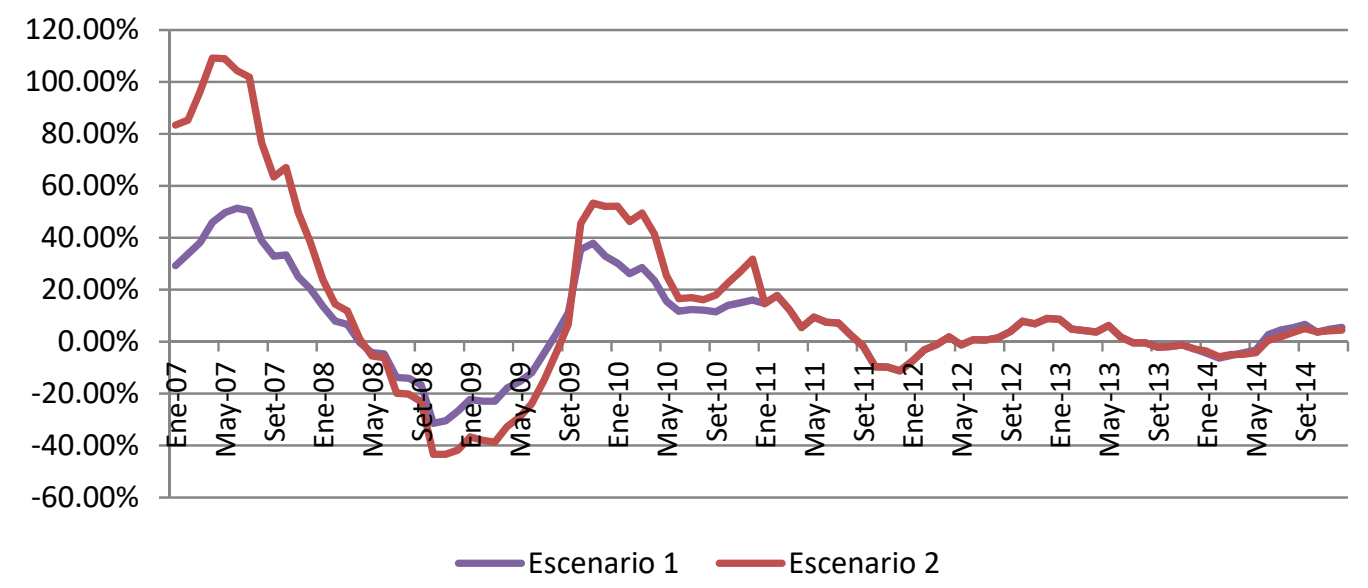

Elaboración Propia

Para esclarecer esta interrogante se recurre al Índice de Sharpe para evaluar el desempeño financiero de ambos escenarios, los resultados se muestran a continuación:

Figura 3.3

Comparación del Índice de Sharpe

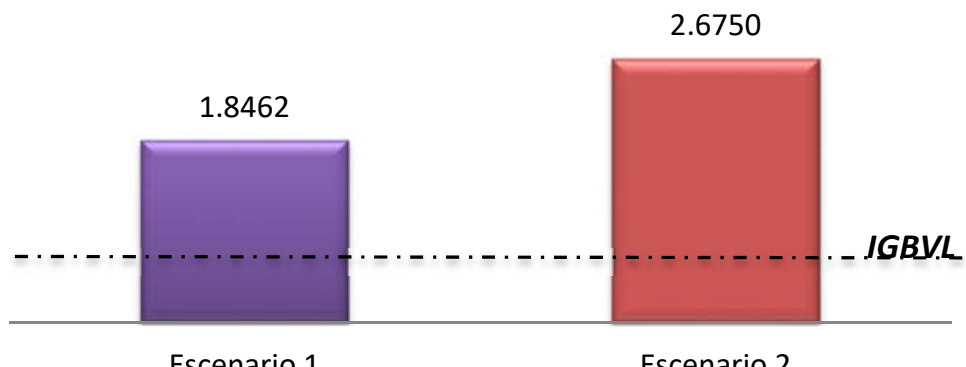

Elaboración propia 
Los resultados mostrados permiten apreciar que el segundo escenario presentó una rentabilidad por unidad de riesgo mayor que el primer escenario al poseer un índice superior de $2.6750^{29}$.

Esta situación se traduce en el SPP como un incremento del $44.89 \%$ en el retorno final por riesgo asumido del fondo de pensiones del afiliado que decidió usar activamente los Multifondos durante su periodo de aportes obligatorios; es decir, al hacer uso de los tres tipos de fondos disponibles en el sistema según sus preferencias relacionadas con su edad, aversión al riesgo y horizonte temporal durante toda su etapa laboral el afiliado es recompensado con un exceso de rentabilidad por riesgo superior en $44.89 \%$, el cual aumenta el valor esperado de la futura pensión de jubilación.

Asimismo, podemos afirmar al igual que Chaparro y Foxley (2010) que durante el periodo de estabilidad económica fue más ventajoso, en términos de desempeño financiero, poseer una cartera con un mayor componente de renta variable como el Fondo Tipo 3 ya que se aprovechó de las fuertes ganancias en rentabilidad que esta opción brindaba.

Sin embargo, el uso de este mismo fondo en el escenario 2 en un periodo de inestabilidad económica (2008-2009) significó pérdidas mayores a las del escenario 1 que estaba conformado por un fondo más conservador con menor proporción de renta variable.

Un punto positivo a rescatar para ambos escenarios es que más allá del beneficio de la reforma de los Multifondos, las empresas administradoras de los fondos privados de pensiones obtuvieron mejores resultados que el mercado bursátil peruano, al ser medidos con esta medida de desempeño donde los resultados de los dos escenarios es mayor que el logrado por el IGBVL en el periodo seleccionado; esto significa que los afiliados recibieron mayores rentabilidades en el SPP de las que hubieran obtenido si es que hubieran destinado sus aportes a una inversión pasiva en el IGBVL.

${ }^{29}$ El índice de Sharpe se realizó con un intervalo de confianza de 98.01\% según lo obtenido con el programa Risk Simulator2014 (ver anexo 3) 
Figura 3.4

Relación Rentabilidad-Riesgo

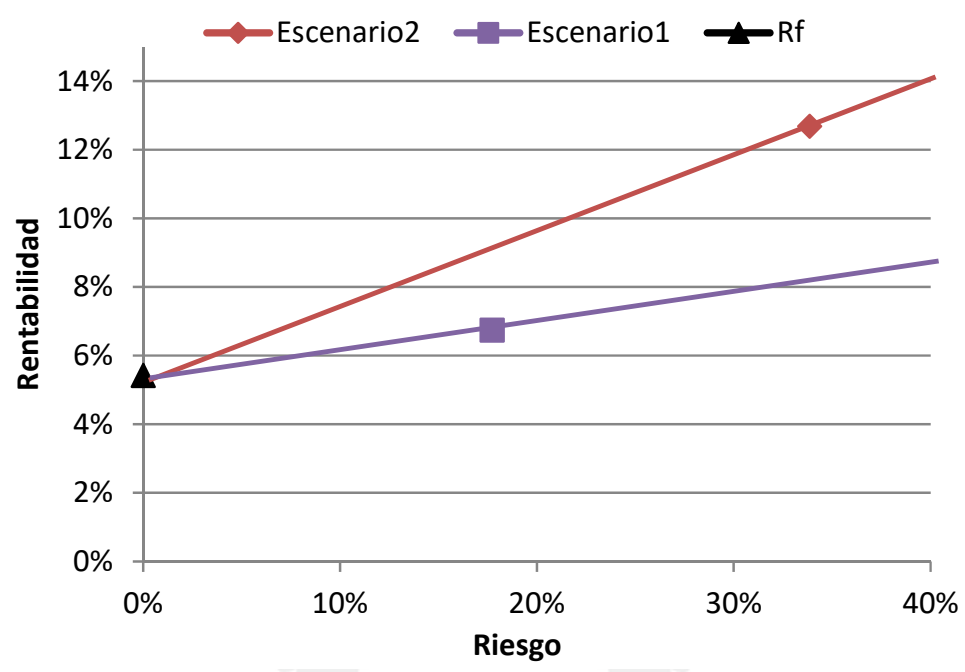

Elaboración propia

Finalmente, para complementar los resultados que validad la afirmación de que el uso activo de los fondos múltiples tiene un efecto positivo en las rentabilidades del SPP se construyó fronteras de posibilidades de inversión que relacionan la rentabilidad y el riesgo para cada escenario. Esta evaluación no hubiera podido ser visualizada sin la presencia de la tasa libre de riesgo, ya que como afirma Rivas-Llosa y Camargo (2002) gracias a la línea trazada desde esta tasa hasta el punto donde se combina el rendimientoriesgo de la cartera se puede construir esta frontera.

En este caso luego de construir ambas fronteras tomando como tasa libre de riesgo la tasa del bono soberano peruano ${ }^{30}$ se concluye que el segundo escenario ofrece una opción de inversión preferible para cualquier inversionista que busque la eficiencia financiera puesto que para cualquier nivel de riesgo seleccionado este escenario ofrece una rentabilidad esperada mayor que la otra opción, y al mismo tiempo, para cualquier nivel de retorno escogido, el riesgo al que se expone es menor.

${ }^{30}$ La SBS presenta una relación de tasas de interés de los bonos soberanos peruanos en soles para diferentes periodicidades, en este caso se tomó la tasa a 8 años para que coincida con el número de años que comprende el periodo seleccionado para el estudio. 


\subsubsection{Implicancias de la crisis financiera}

Como se dedujo en la sección anterior, el comportamiento real de la cartera administrada por el SPP está relacionado con el contexto económico. Es por este motivo que es preciso analizar las implicancias de la crisis financiera del 2008 en nuestro análisis que abarca del año 2007 hasta el año 2014.

Una investigación importante sobre el efecto de las crisis económicas es la de Roldos (2007), que encuentra una relación del 80\% de las crisis económicas con el descenso de los retornos de los portafolios de inversión de los fondos de pensiones en Latinoamérica. De este mismo modo, pero con un mayor enfoque a la coyuntura nacional, Duarte Ojeda (2012) menciona lo siguiente:

El desempeño del sistema (privado de pensiones) ha sufrido las consecuencias de las crisis externas de los mercados financieros, resultando en pérdidas importantes en el nivel de cuentas de los afiliados, como resultado de la predicción del modelo, en promedio ha sido de un monto de 10 mil nuevos soles para el periodo de 2008 solamente. (p. 263)

Esta relación existente entre la inestabilidad económica y las pérdidas en los fondos de pensiones se da a partir del impacto que generan las crisis en el desempeño del mercado bursátil local e internacional en las inversiones que las AFP realizan en estas bolsas. Para ejemplificar, la caída más pronunciada del IGBVL en todo el periodo seleccionado fue de $-37.28 \%$ en octubre del 2008 y esta desencadenó una pérdida de rentabilidad de $-13.69 \%,-31.47 \%$ y - 43.36\% para los Fondos Tipo 1,2 y 3 respectivamente; lo cual significó una pérdida en la cartera administrada por el sistema de S/. 8,587 millones de nuevos soles.

Otro efecto de la crisis internacional del 2008 sobre el sistema fue el cambio en la composición de la cartera de los fondos de pensiones principalmente en la participación del rubro "Sistema no financiero" que tuvo una caída al descender en $60 \%$ el monto invertido en acciones entre junio del 2007 y diciembre del 2008 como respuesta al fin de la burbuja bursátil ${ }^{31}$ tal como lo concluyen Rojas y Távara (2011).

A fin de tener una mejor del impacto de la crisis financiera en nuestro análisis, se presenta una serie de indicadores separando nuestros años seleccionados de análisis en

\footnotetext{
${ }^{31}$ Los autores se refieren con burbuja bursátil al escenario económico de auge en los índices de las bolsas internacionales (entre las que se encuentra la BVL) a partir del año 2004
} 
dos etapas: un periodo sin considerar esta fase de la actividad económica y un periodo que solo comprende este suceso global.

Tabla 3.2

Periodo ex-ante, ex-post crisis financiera, 2007; 2010-2014

\section{Escenario 1 Escenario 2}

\begin{tabular}{|l|cc|}
\hline Rentabilidad & $10.54 \%$ & $19.88 \%$ \\
Varianza & $2.31 \%$ & $10.33 \%$ \\
Desv. Est. & $15.19 \%$ & $32.14 \%$ \\
Coef. Variación & 1.441 & 1.617 \\
\hline
\end{tabular}

Elaboración propia

Los resultados obtenidos muestran que la volatilidad de los fondos de pensiones fue evidentemente mayor en el periodo de crisis (tanto la varianza como la desviación estándar y el coeficiente de variación fueron mayores para el segundo periodo), lo cual concluye que si bien la crisis tuvo un efecto negativo en todo el sistema de pensiones cada escenario se vio afectado manera distinta y estas caídas fueron menos notorias en el escenario 1 de cartera menos riesgosa y más conservadora al presentar un componente mayor de renta fija.

Tabla 3.3

Periodo de crisis financiera, 2008-2009

Escenario 1 Escenario 2

\begin{tabular}{|l|cc|}
\hline Rentabilidad & $2.91 \%$ & $4.17 \%$ \\
Varianza & $3.99 \%$ & $9.98 \%$ \\
Desv. Est. & $19.97 \%$ & $31.60 \%$ \\
Coef. Variación & 6.853 & 7.573 \\
\hline
\end{tabular}

Elaboración propia 
A modo de conclusión, las implicancias mencionadas demuestran que la crisis del año 2008 ocasionó una contracción de los fondos del sistema de pensiones que dará lugar, sin dudas, a pensiones de jubilación menores a las esperadas de los trabajadores afiliados.

Otras variables que también se discutieron en trabajos especializados son la recomposición de la estructura del cobro de comisiones y las rentabilidades de las AFP; sin embargo, estos temas escapan de los objetivos de la presente investigación ${ }^{32}$.

\subsubsection{Paradoja de Feldstein-Horioka}

Siguiendo con la investigación, a continuación se analizará el efecto del SPP sobre la inversión peruana; para poder cuantificar este impacto se utilizó una ecuación inspirada en la paradoja resultante del trabajo de Feldstein y Horioka (1980).Sin embargo, según Gujarati (2009) antes de profundizar en los resultados de la ecuación es de suma importancia verificar si las series de tiempo a utilizar no presentan estacionariedad ${ }^{33}$, porque ello afecta a los resultados que se pretenden obtener al llevar a distorsiones como relaciones espúreas o resultados pocos significativos.

Una de las pruebas para comprobar si las variables utilizadas son estacionarias es la prueba de raíz unitaria ${ }^{34}$. Si bien existen diversas pruebas que determinan la presencia o no de estacionariedad se ha seleccionado la Prueba de Phillips-Perron (PP), la cual utiliza métodos estadísticos no paramétricos para evitar la correlación serial en los términos de error, sin añadir términos de diferencia rezagados y obtener una estimación insesgada. (Gujarati, 2009)

Los resultados obtenidos para las variables utilizadas son los siguientes:

\footnotetext{
32 Véase los artículos siguientes:

Mayorga, V. (2009) "Crisis financiera mundial y sus efectos en el SPP: problemas y medidas de protección de los fondos de los afiliados"

Mayorga, V. (2009) "Proyectos de Ley presentados a la Comisión de Seguridad Social acerca del SPP en un escenario de crisis"

Rojas, O. y Távara, J. (2011) "El SPP en el contexto de crisis"

${ }^{33}$ Una serie de tiempo es estacionaria, de manera informal, si sus características (por ejemplo, media, varianza y covarianza) son invariantes respecto del tiempo; es decir, no cambian en relación con el tiempo - Gujarati,2009

${ }^{34}$ Es una característica de las variables que evolucionan a través del tiempo y que puede causar problemas en inferencia estadística en modelos de series de tiempo. (Gujarati,2009)
} 
Tabla 3.4

Prueba de Raíz Unitaria - Inversión

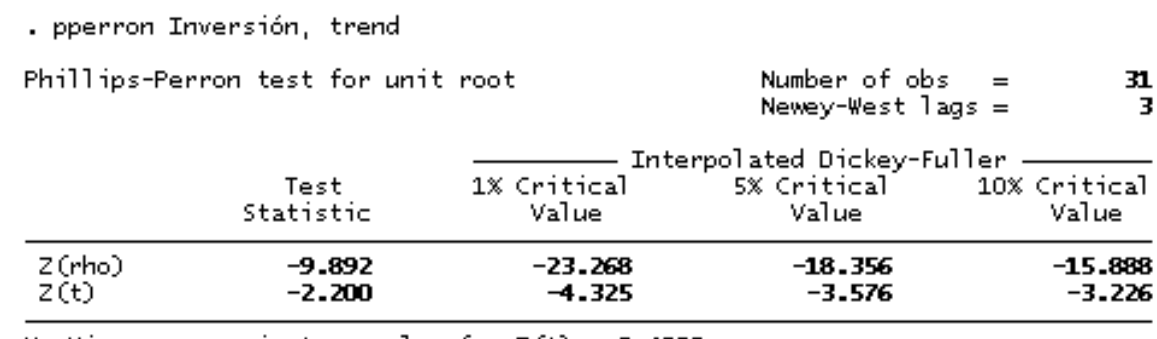

Mack innon approximate $p$-val Le for $z(t)=0.4898$

Elaboración propia - Stata10

Tabla 3.5

Prueba de Raíz Unitaria - Cartera Administrada SPP

\begin{tabular}{|c|c|c|c|c|}
\hline \multirow[t]{2}{*}{ Fhi11 ip } & \multirow{2}{*}{$\begin{array}{l}\text { n test for Lunit } \\
\text { Test } \\
\text { statistic }\end{array}$} & \multirow{2}{*}{$\begin{array}{l}\text { root } \\
\begin{array}{c}1 \times \text { Critical } \\
\text { value }\end{array}\end{array}$} & \multirow{2}{*}{ 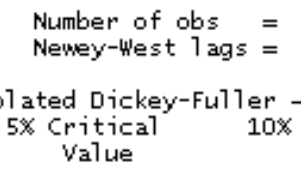 } & \multirow{2}{*}{$\begin{array}{r}\mathbf{3 1} \\
\begin{array}{c}\text { Critical } \\
\text { Value }\end{array}\end{array}$} \\
\hline & & & & \\
\hline $\begin{array}{l}z(r h o) \\
z(t)\end{array}$ & $\begin{array}{l}-9.179 \\
-2.136\end{array}$ & $\begin{array}{r}-23.2668 \\
-4.325\end{array}$ & $\begin{array}{r}-18.356 \\
-3.576\end{array}$ & $\begin{array}{r}-15.8888 \\
-3.226\end{array}$ \\
\hline
\end{tabular}

Mackinnon approximate $p$-walue for $z(t)=0.5260$

Elaboración propia - Stata10

Tabla 3.6

Prueba de Raíz Unitaria - Ahorro Público

- pperron Ahorrofub, trend

Fhillips-Ferron test for whit root

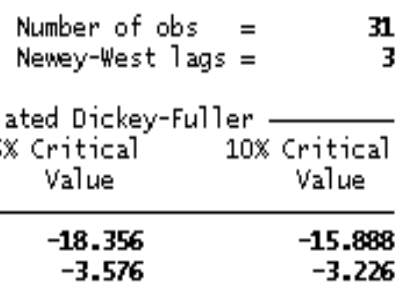

Mackinnon aproximate p-value for $Z(t)=0.1582$

Elaboración propia - Stata10 
A partir de las tablas se puede observar que las tres variables de la ecuación tienen raíces unitarias, lo que justifica que en la regresión se divida las variables sobre el PBI para convertirlas en estacionarias.

Una vez verificado la estacionariedad de las variables es posible calcular la regresión. Con la finalidad de ayudar a la mejor comprensión de los parámetros hallados se ha utilizado las variables en logaritmos para poder interpretarlas como elasticidades y que los coeficientes obtenidos expliquen mejor la relación de la inversión total doméstica con la cartera administrada por el SPP y el ahorro público.

Tabla 3.7

Resultado Regresión: Inversión-Ahorro

- reg inversion SPF ahorropub

\begin{tabular}{r|ccc} 
Source & $S 5$ & df & MIS \\
\hline Mode1 & $\mathbf{- 3 1 4 1 1 0 9 9 1}$ & 2 & $\mathbf{- 1 5 7 0 5 5 4 9 6}$ \\
Residual & $\mathbf{- 1 8 4 1 5 8 3 9 9}$ & 29 & $\mathbf{- 0 0 6 3 5 0 2 9}$ \\
\hline Total & $\mathbf{- 4 9 8 2 6 9 3 9 1}$ & 31 & $\mathbf{- 0 1 6 0 7 3 2 0 6}$
\end{tabular}

NLtumber of obs = 32

FC 2, 29$)=24.73$

Frob $=F=0.0000$

Ri-squaried = 0.6304

Adj Ri-sqLiared $=0.6049$

Root $\mathrm{HSE}=\mathbf{- 0 7 9 6 9}$

\begin{tabular}{|c|c|c|c|c|c|c|}
\hline inversion & Coef. & Std. Erre. & $t$ & $P=1+1$ & [95\% Gonf. & Interval ] \\
\hline $\begin{array}{r}\text { SFP } \\
\text { ahorropub } \\
\text { _Cons }\end{array}$ & $\begin{array}{l}.2483175 \\
.6458796 \\
3.552836\end{array}$ & $\begin{array}{l}-1584734 \\
-0934198 \\
-4732082\end{array}$ & $\begin{array}{l}1.57 \\
6.91 \\
7.51\end{array}$ & $\begin{array}{l}0.128 \\
0.000 \\
0.000\end{array}$ & $\begin{array}{r}-.0757971 \\
-4547548 \\
2.585016\end{array}$ & $\begin{array}{r}.572432 \\
.8369845 \\
4.520655\end{array}$ \\
\hline
\end{tabular}

Elaboración Propia- Stata10

Los resultados encontrados con la regresión están acordes a las relaciones económicas planteadas inicialmente entre los componentes de ahorro e inversión, donde se espera que exista una relación directa entre estas variables, pues tanto el coeficiente del SPP como el del ahorro público nacional son positivos.

En el caso de los fondos del sistema privado de pensiones el efecto sobre la inversión total nacional es de 0.2483 ; lo cual indica que ante la variación del monto de la cartera administrada por el sistema de pensiones del 1\% la inversión varía en $0.2483 \%$. Así también el impacto del ahorro público doméstico en el modelo es 0.6458 , este parámetro tiene la misma interpretación que la variable anterior en la inversión total del 
país. En este caso, el parámetro encontrado registra un mayor impacto al tener una aplicación inmediata sobre la inversión; es decir, el uso de ahorro público se materializa en inversión nacional según las disposiciones directas del Gobierno, por ejemplo, el aumento del gasto en infraestructura se traduce en un incremento en la inversión nacional mediante el aumento en la inversión pública de manera directa y completa.

Con estos parámetros, principalmente con el $\alpha_{1}$ de 0.2483 asociado al SPP, se concluye que el aumento en la tasa de ahorro atribuible a la reforma pensionaria contribuye a un aumento en la tasa de inversión total, esta afirmación se sustenta en el hecho que las AFP invierten parte de los fondos captados en instrumentos locales dentro el límite establecido por la SBS lo cual se ve reflejado en la inversión total peruana.

Esta afirmación también se concluyó para Chile en el estudio de Corbo y SchmidtHebbel (2003) donde encontraron que el coeficiente $\alpha_{1}$ fue de 0.5116 para el periodo 1981-2001.

\subsection{Análisis de proyecciones y tendencias}

Complementando lo analizado en el presente capítulo, se realizó algunas proyecciones anuales para los efectos en la inversión total basadas en las proyecciones para el ahorro público y privado ${ }^{35}$ del Marco Macroeconómico Multianual (MMM) 2016-2018 y las elasticidades obtenidas en la regresión anterior.

Tabla 3.8

Proyecciones anuales de la inversión total, 2013-2018

\begin{tabular}{|c|c|c|}
\hline \multicolumn{3}{|c|}{ Proyecciones MMM $2016-2018$} \\
\hline Año & Ahorro Priv. & Ahorro Pub. \\
\hline 2013 & $16.90 \%$ & $7 \%$ \\
\hline 2014 & $16.80 \%$ & $6.10 \%$ \\
\hline 2015 & $17.50 \%$ & $4.50 \%$ \\
\hline 2016 & $18.20 \%$ & $4.70 \%$ \\
\hline 2017 & $18.90 \%$ & $4.80 \%$ \\
\hline 2018 & $19.30 \%$ & $5.20 \%$ \\
\hline
\end{tabular}

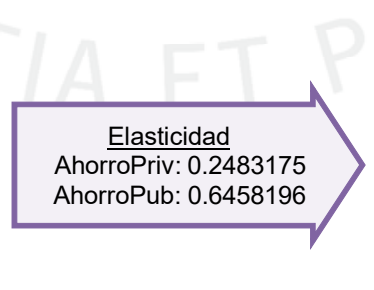

\begin{tabular}{|c|c|c|}
\hline \multirow{2}{*}{ Año } & \multicolumn{2}{|c|}{ Inversión Total } \\
\hline 2013 & $4.20 \%$ & $4.52 \%$ \\
\hline 2014 & $4.17 \%$ & $3.94 \%$ \\
\hline 2015 & $4.35 \%$ & $2.91 \%$ \\
\hline 2016 & $4.52 \%$ & $3.04 \%$ \\
\hline 2017 & $4.69 \%$ & $3.10 \%$ \\
\hline 2018 & $4.79 \%$ & $3.36 \%$ \\
\hline
\end{tabular}

Elaboración Propia

\footnotetext{
${ }^{35}$ Se utilizaron las proyecciones de ahorro privado como proxy para la cartera administrada del SPP ante la no disponibilidad de proyecciones específicas para esta variable
} 
De acuerdo a las proyecciones del MMM el ahorro privado presenta una tendencia creciente lo cual favorece la contribución al crecimiento de la inversión total nacional; sin embargo, el ahorro público se proyecta con rangos descendientes lo cual responde según la planificación estatal al uso eficiente de esta variable para mantener el ratio de deuda pública inferior a los países con igual calificación crediticia y al adecuado financiamiento de los déficit fiscales que se proyectan en el MMM 2016-2018.

Al ser elasticidades las utilizadas para proyectar la interpretación para el último año proyectado es que el valor de $19.3 \%$ del ahorro privado y de $5.2 \%$ del ahorro público impactará en el incremento en la inversión total nacional con contribuciones de $4.79 \%$ y $3.36 \%$ respectivamente.

Asimismo, se construyó proyecciones basadas en tendencias de crecimiento para las variables más relevantes: Inversión Total Nacional y Cartera Administrada por el SPP; planteando tres escenarios (optimista, conservador y pesimista).

Para el escenario optimista se utilizó una tendencia exponencial, para el escenario pesimista se usó una tendencia cuadrática y el escenario conservador es el promedio simple de los dos escenarios extremos.

Figura 3.5

Proyección de tendencias - Inversión, 2007-2016

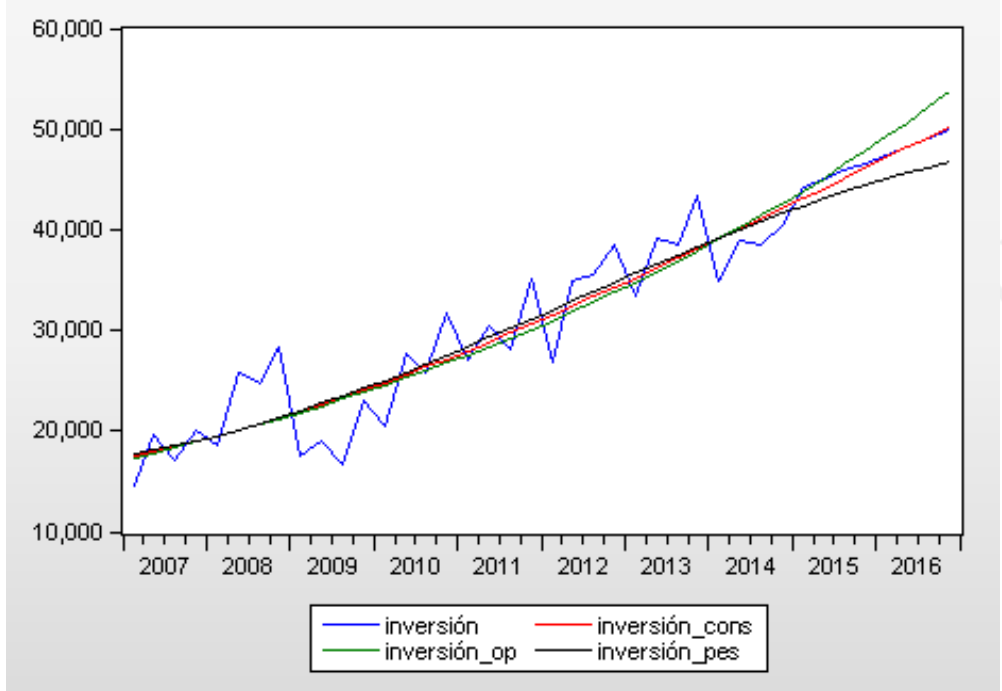

Elaboración Propia - Eviews7 
Figura 3.6

Proyección de tendencias - Cartera Administrada del SPP, 2007-2016

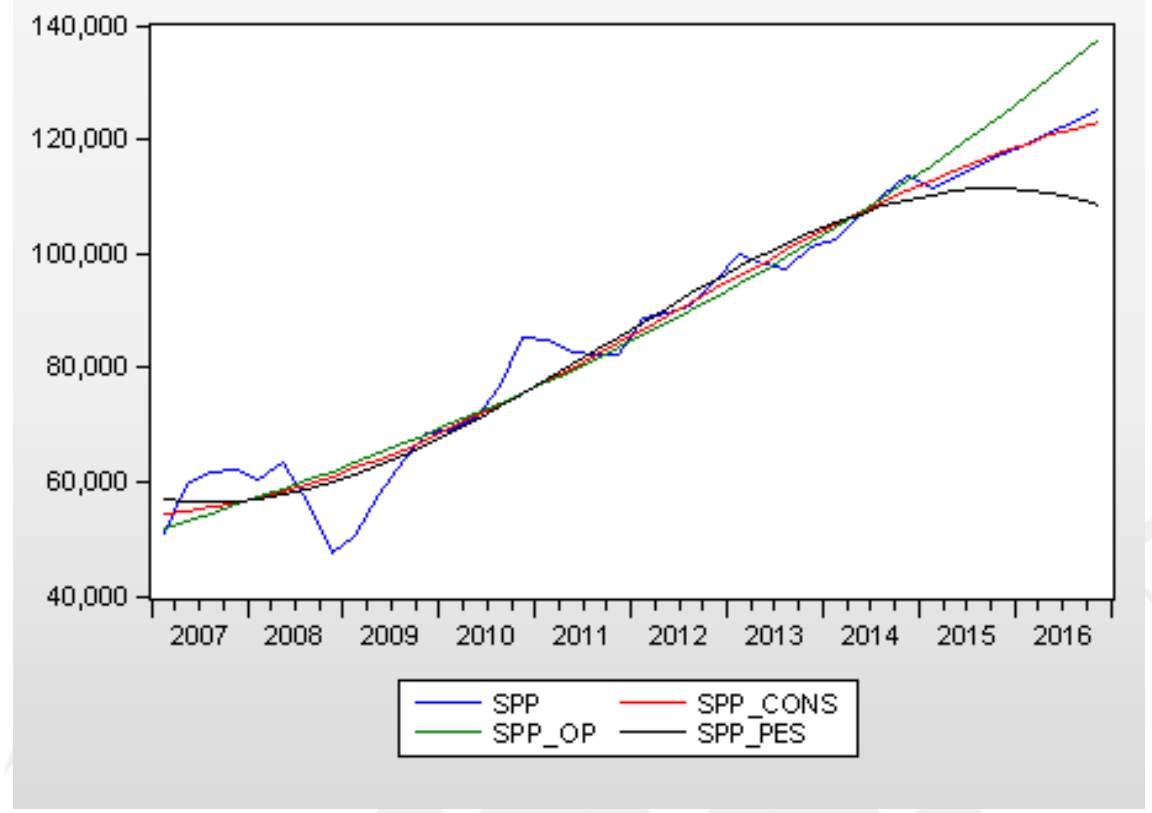

Elaboración Propia - Eviews7

Las tendencias de crecimiento muestran una mayor volatilidad de los recursos del Sistema Privado de Pensiones ante escenarios poco favorables para la actividad económica, lo cual se vincula al tema analizado anteriormente sobre la relación de los fondos del sistema con la situación económica del país; de igual forma cuando hay un periodo de auge el crecimiento de los recursos que invierten las AFP aumenta fuerte.

En el caso de la inversión, esta variable no presenta variaciones tan marcadas ya que como se incluye también el ahorro público si el sector privado comienza descender enérgicamente el Estado hace uso de los excedentes nacionales para evitar consecuencias substanciales en la economía. 


\subsection{Diagnóstico y comentarios finales}

La importancia de este capítulo era hallar los resultados prácticos para poder contrastar con las hipótesis planteadas en la investigación y finalizar con conclusiones apropiadas.

Por un lado, con los resultados obtenidos usando el índice de Sharpe y las fronteras de inversión se comprobó la primera hipótesis específica que explica la reforma de los Multifondos otorga mayores rentabilidades frente al esquema anterior, y por ende un aumento en la pensión de jubilación futura.

Por otro lado, en base al coeficiente resultante de la ecuación de Feldstein-Horioka se contrastó la segunda hipótesis que marca un efecto directo entre la tasa de ahorro que genera las reformas del sistema de pensiones en la inversión total nacional al destinar la una parte importante de los recursos de los afiliados a instrumentos locales.

A modo de conclusión se puede afirmar que la utilización de los fondos múltiples ha tenido un impacto positivo y significativo tanto en el Sistema Privado de Pensiones como en la inversión total nacional en el periodo que inicia en el año 2007 y finaliza en el año 2014. En los capítulos siguientes se desarrollarán las conclusiones para todos los objetivos tanto el general como los específicos y se formularán algunas recomendaciones que pueden ser aplicadas o de utilidad en algún trabajo futuro o simplemente ayuden al lector a comprender mejor el tema. 


\section{CONCLUSIONES}

- La reforma de los Multifondos proporciona un efecto beneficioso en el Sistema Privado de Pensiones peruano puesto que al establecer una estrategia de inversión utilizando los tres tipos de fondos disponibles basada en el ciclo de vida del afiliado y sus preferencias por riesgo en cada etapa del periodo laboral se obtiene una rentabilidad $44.8 \%$ mayor que la obtenida utilizando únicamente el fondo conservador, lo cual se traducirá en incrementos de los recursos administrados por el sistema y en un mayor valor esperado de la pensión de jubilación futura.

- La crisis financiera internacional del año 2008 impactó severamente al sistema de pensiones peruano al reducir las rentabilidades de todos los fondos y por ende provocando una reducción de S/. 11, 170.108 millones en la cartera administrada; sin embargo, la proporción de pérdida fue diferente para cada fondo disponible y el más afectado fue el fondo tipo 3 al obtener una rentabilidad promedio mensual de $-8.9 \%$ durante este año. Este resultado afectó el retorno de los afiliados que utilizaron el fondo más agresivo del esquema Multifondos pero estas pérdidas fueron compensadas con las ganancias que el mismo fondo proporcionó en los otros años, finalizando con una rentabilidad final promedio positiva mensual de $12.5 \%$ en el periodo comprendido por los años 2007-2014.

- El ahorro privado proveniente de los aportes obligatorios administrados por el Sistema Privado de Pensiones impacta en la inversión total nacional en $24.83 \%$ durante el periodo seleccionado; es decir, por cada sol aportado por los afiliados en el esquema de fondos múltiples la inversión peruana tanto pública como privada creció en 0.2483 soles, contribuyendo al crecimiento económico del país. Este incremento se justifica en las inversiones realizadas por las Administradoras de Fondos de Pensiones en instrumentos financieros locales como acciones, bonos, certificados de depósito, entre otros. 


\section{RECOMENDACIONES}

- La Superintendencia de Banca, Seguros y AFP debería promocionar la gestión activa del uso de los fondos múltiples que ofrece el Sistema Privado de Pensiones ya que si bien la reforma entró en funcionamiento en el 2005, a Diciembre del 2014 el 90.28\% de los afiliados continua ubicándose en el fondo conservador que existe en el sistema desde sus inicios, pues es el fondo en el que la empresa administradora escogida coloca los fondos inicialmente y se mantiene durante toda la vida laboral por falta de solicitud de cambio por parte del usuario; y solo el $9.72 \%$ restante opta por luego trasladarse a los otros fondos siguiendo sus preferencias; lo que refleja el leve impacto de la reforma. Para que el afiliado comprenda mejor los beneficios del uso de los Multifondos se debería incentivar el desarrollo de una cultura bursátil básica que le permita comprender el esquema e indicadores de los tipos de fondos disponibles cuando reciben las cartillas de rentabilidad de la AFP en la que se encuentra, de esta manera podría tomar decisiones más informadas a lo largo de su periodo de aportes.

- Los fondos pensionarios deberían estar protegidos ante escenarios nacionales e internacionales desfavorables que puedan provocar pérdidas severas como las crisis financieras con regulaciones especializadas que impulsen a que las AFP reacciones con mayor rapidez y puedan realizar inversiones que aminoren las rentabilidades negativas. Acorde a esta posibilidad el Congreso peruano ha lanzado diversos proyectos de ley para que las empresas administradoras compartan los riesgos con los afiliados y la creación de otro fondo con límites específicos para escenarios adversos.

- Si bien se encontró una relación positiva entre el ahorro generado por los fondos múltiples del Sistema Privado de Pensiones y la inversión total nacional, lo cual revela la importancia de estos recursos en el crecimiento del país, la investigación referente a este tema podría ser más detallada al agregar variables a la ecuación utilizada o escoger otra metodología para afinar los parámetros obtenidos y poder cuantificar con mayor precisión el efecto de las reformas pensionarias en la inversión pública y privada local. 


\section{REFERENCIAS}

Alexander, G., Sharpe, W. y Bailey, J. (2003). Fundamentos de inversiones: teoría y práctica. México D.F: Pearson Educación.

Apoyo Consultores (2010). Importancia del Sistema Privado de Pensiones en el Perú. Lima: Apoyo Consultores.

Banco Mundial (1990). La Reforma del Estado Peruano. Washington DC: Banco Mundial, Annex 2 Working Document.

Banco Mundial (1994). Envejecimiento sin crisis: Politicas para la protección de los ancianos y promoción del desarrollo. Washington DC: Banco Mundial.

Bayoumi, T. (1990). Saving-investment Correlations. Immobile Capital, Government Policy or Endogenous Behaviour. IMF: Staff Papers. (37), pp. 360-387.

Bernal, N., Muñoz, A., Perea, H., Tejada, J. y Tuesta, D. (2008). Una mirada al Sistema Peruano de Pensiones: Diagnóstico y propuestas. Lima: BBVA.

Blanchard, O. y Fischer, S. (1994) Lectures on Macroeconomics. Cambridge Massachusetts: The MIT Press.

Boloña, C. (1995). ¿Dueño de tu jubilación? Lima: Instituto de Economía de Libre Mercado.

Calderón, C. y Schmidt-Hebbel, K. (2003). Learning the Hard Way: Ten Lessons for Latin America. Chile: Banco Central de Chile, Documento de Trabajo No 217.

Chaparro, A. y Foxley, J. (2010). El desempeño ajustado por riesgo de los multifondos de pensiones en Chile. Santiago de Chile: Universidad Alberto Hurtado/School of Economics and Business.

Congreso de la República (2009). Crisis financiera mundial y sus efectos en el Sistema Privado de Pensiones: Problemas y medidas de protección de los fondos de los afiliados. Lima: Congreso de la República, Comisión de Seguridad Social.

De Gregorio Rebeco, J. (2007). Macroeconomía: teoría y políticas. Ciudad de México: Pearson Educación. 
Duarte Ojeda, J. R. (2012). Evaluación del desempeño económico de los sistemas de pensiones privados en Latinoamérica. Sociedad y Economía, (21), 243-266.

Dirección General de los Asuntos Económicos y Sociales (2004). Informe trimestral: Los Sistemas de Pensiones en el Perú. Lima: Ministerio de Economía y Finanzas.

Feldstein, M. (1983). Domestic saving and international capital movements in the long run and the short run. European Economic Review, 21(1), 129-151.

Feldstein, M. y Horioka, C. (1980). Tax Policy and International Capital Flows. Economic Journal, 90, 314-329.

Feldstein, M. y Bacchetta, P. (1991). National saving and international investment. National saving and economic performance. University of Chicago Press, 201-226.

Federación Internacional de Administradoras de Fondos de Pensiones (2003). Resultados y Desafios de las Reformas a las Pensiones. Ciudad de México: FIAP.

Galarza, R. (2001). II Conferencia Internacional de Fondos de Pensiones. Santiago de Chile

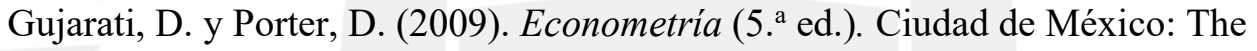
McGraw-Hill Companies, Interamericana Editores.

Herscovich, H. (2003). La utilización de Multifondos en el sistema de pensiones chilenoEl caso CUPRUM. Buenos Aires: Universidad de San Andrés.

Hidalgo, D. (2004). Hechos cumplidos vs. derechos adquiridos: alcances de la reforma constitucional a propósito del decreto ley 20530. Derecho y cambio social, 1(1).

Jansen, J. y Schulze, G. (1996). Theory based Measurement of the Saving-Investment Correlation with an Application to Norway. Economic Inquiry. 33, 116-132.

Kapsoli, J., Rodriguez, J., Masías, I., Sánchez, E., Quiñones, J. y Clausen, M. (2007). Plan de mejoras al SNP y al Sistema Privado de Administración de Fondos de Pensiones que permitan asegurar su coexistencia en el mediano y la propuesta de nueva política de inversiones del fondo consolidados de reservas previsionales. Lima: Informe Final de la Comisión Tecina, Ley № 28991, DS Nº51-2007-EF.

Kritzman, M. (1994). What practitioners need to know About Future Value. Financial Analysts Journal, May/June 94. 
Ley $\mathrm{N}^{\circ}$ 25967, Ley del Sistema Privado de Administración de Fondos de Pensiones. (12 de diciembre de 1992). Recuperado del sitio de internet del Congreso de la República: http://www4.congreso.gob.pe/historico/cip/materiales/ronp/DL25967.pdf

Markowitz, H. (1952). Portfolio Selection. Journal of Finance, 7(1).

Mendiola, A., Aguirre, C., Buendía, D., Chong Shing, J., Segura M. y Segura, M.A. (2013). Análisis del sistema privado de pensiones: propuesta de reforma y generación de valor. Lima: Universidad ESAN.

Mesa-Lago, C. (1985). Desarrollo de la seguridad social en América Latina. Santiago de Chile: Naciones Unidas.

Mesa-Lago, C. (1991). Portfolio performance of selected Social Security institutes in Latin America. Washington DC: Banco Mundial.

Montoro, C. (1999). Costo de la reforma del Sistema Nacional de Pensiones: Una adaptación del modelo de generaciones traslapadas. Revista de Estudios Económicos BCRP, 4.

Morón, E. y Carranza, E. (2003). Diez años del Sistema Privado de Pensiones (19932003): avances, retos y reformas. Lima: Universidad del Pacifico.

Muñoz, I. (1999). La reforma del Sistema Privado de Pensiones. Lima: Instituto Peruano de Economía.

Narayan, P. K. (2005). The relationship between saving and investment for Japan. Japan and the world economy, 17, $293-309$.

Organización Internacional del Trabajo (1991). Administración de la Seguridad Social. Ginebra: OIT.

Pelagidis, T., y Mastroyiannis, T. (2003). The saving-investment correlation in Greece, 1960-1997: Implications for capital mobility. Journal of Policy Modeling, 25, 609616.

Pereda, Javier (2007). Estimación de la Frontera Eficiente para las AFP en el Perú y el Impacto de los Límites de Inversión: 1995-2004. Lima: Banco Central de Reserva del Perú.

Rivas-Llosa, R. y Camargo, G. (2002). Eficiencia financiera de los límites de inversión para las AFPs: una aplicación al caso peruano. Lima: Universidad del Pacífico. 
Roldós, J. E. (2007). Pension reform and macroeconomic stability in Latin America. IMF Working Papers, 1-32.

Rojas, J. (2003). El sistema privado de pensiones y su papel en la economía peruana. Economía y Sociedad - CIES, 50, 14-20.

Rojas, J. y Távara, J. (2010). El Sistema Privado de Pensiones en el contexto de crisis. Lima: Congreso de la República.

Sharpe, W. (1976). Teoría de cartera y del mercado de capitales. New York: McGrawHill education.

Texto Único Ordenado de la Ley del SPP - TUO (14 de mayo de 1997). Recuperado del sitio de internet de la Superintendencia de Banca, Seguros y AFP: https://www.sbs.gob.pe/principal/categoria/sistema-privado-de-pensiones/2591/c-2591

Titelman, D., Pérez-Caldentey, E., y Minzer, R. (2008). Una comparación de la dinámica e impactos de los choques de términos de intercambio y financieros en América Latina 1980-2006. Santiago de Chile: Comisión Económica para América Latina y el Caribe (CEPAL).

Uthoff,A. (1995). Reforma a los sistemas de pensiones en América Latina. Santiago de Chile: Revista de la CEPAL.

World Bank. 2012. Pensions. Africa social protection policy briefs. Washington DC: World Bank.

Zurita, S. y Jara, C. (1999). Desempeño financiero de fondos de pensiones. Estudios Públicos, 74, 227-254. 


\section{ANEXOS}




\section{Anexo 1: Instrumentos de inversión}

A continuación, se detallan los instrumentos de inversión elegibles por las Administradoras de Fondos de Pensiones según el TUO:

a) Valores emitidos por el Estado Peruano sin incluir el Banco Central de Reserva del Perú;

b) Valores emitidos o garantizados por el Banco Central de Reserva del Perú;

c) Valores emitidos por instituciones pertenecientes al sector público diferentes del Banco Central de Reserva del Perú garantizados por el Gobierno Central o el Banco Central;

d) Valores emitidos por instituciones pertenecientes al sector público diferentes del Banco Central de Reserva del Perú;

e) Depósitos a plazo y otros títulos representativos de captaciones por parte de empresas del Sistema Financiero;

f) Bonos emitidos por personas jurídicas pertenecientes o no al Sistema Financiero;

g) Instrumentos de inversión emitidos para el financiamiento hipotecario por empresas bancarias o financieras, y sus subsidiarias;

h) Instrumentos de inversión emitidos para el financiamiento hipotecario por otras entidades con o sin garantía del Fondo MIVIVIENDA u otras instituciones;

i) Otros Instrumentos de corto plazo distintos a los de captación por parte de las empresas del Sistema Financiero;

j) Operaciones de reporte;

k) Acciones y valores representativos de derechos sobre acciones en depósito inscritos en una Bolsa de Valores;

1) Certificados de suscripción preferente;

m) Productos derivados de valores que se negocien en Mecanismo Centralizado de Negociación;

n) Operaciones de cobertura de los riesgos financieros y gestión eficiente de portafolio;

o) Cuotas de participación de los Fondos Mutuos de Inversión en Valores y de los Fondos de Inversión;

p) Instrumentos de inversión representativos de activos titulizados; 
q) Instrumentos financieros emitidos o garantizados por Estados y Bancos Centrales de países extranjeros; así como acciones y valores representativos de derechos sobre acciones en depósito inscritos en Bolsas de Valores; instrumentos de deuda, cuotas de participación de fondos mutuos y operaciones de cobertura de riesgo emitidas por instituciones extranjeras;

r) Emisiones primarias de acciones y/o valores mobiliarios representativos de derechos crediticios dirigidos a financiar el desarrollo de nuevos proyectos;

s) Pagarés emitidos o avalados por empresas del Sistema Financiero;

t) Pagarés emitidos y avalados por otras entidades;

u) Inversión directa a través de títulos de deuda o acciones, así como instrumentos financieros destinados al desarrollo de proyectos de inversión en infraestructura, concesiones, vivienda, explotación de recursos naturales y bosques cultivados $\mathrm{u}$ otros sectores que por sus características requieran financiamiento de mediano y largo plazo;

Otros instrumentos u operaciones que autorice la Superintendencia

Fuente: Reglamento del Texto Único Ordenado de la Ley del Sistema Privado de Administración de Fondos de Pensiones (TUO- D.S Nº 054-97-EF/ R.S Nº 052-98-EF/SAFP) 


\section{Anexo 2: Cambio de Tipo de fondo}

Según la Cartilla Informativa de los Multifondos que se encuentra en el portal virtual de la Superintendencia de Banca, Seguros y AFP (www.sbs.gob.pe), para que el afiliado pueda cambiar de tipo de fondo deberá presentar una solicitud de cambio a partir del segundo mes siguiente (mes $\mathrm{z}+2$ ) de haber presentado una solicitud de cambio de fondo anterior (mes z), o de haberse afiliado a una AFP. El primer mes de devengue de la CIC del afiliado en el fondo tipo elegido, corresponde al segundo mes siguiente al de la presentación de la solicitud de cambio respectiva.

El cambio de un fondo de pensiones tipo a otro se hace por medio presencial o por medios remotos vía Internet. En este último caso se debe presentar la solicitud de cambio a través del sitio web de la AFP en la que mantenga los aportes que se desean trasladar.

Si el cambio se realiza por medio presencial, el afiliado deberá acudir a la agencia de la AFP que administre su CIC y deberá sujetarse al siguiente procedimiento:

- Recabar un formulario de la solicitud de elección o cambio de fondo de pensiones (también se puede recabar la solicitud directamente con un promotor de la misma AFP).

- Acompañar a la mencionada solicitud copia de su documento de identidad.

Verificado ello satisfactoriamente, se dará inicio al proceso que tarda 60 días aproximadamente, es importante tener en cuenta que se debe guardar la solicitud aceptada por la AFP como prueba de que se ha hecho el trámite ya que esta servirá para cualquier reclamo posterior.

En cambio, si el cambio se realiza por medio remoto el afiliado debe acceder al sitio web de la AFP que administre su CIC y sujetarse al siguiente procedimiento:

- Solicitar una Clave Privada de Seguridad a la AFP.

- Registrar una solicitud electrónica, llenando la información de soporte necesaria: Información referente al afiliado, documento de identidad y lugar de residencia, 
el número de su CIC y el Tipo de Fondo de Pensiones al que pertenece y al que desea pertenecer.

Luego del ingreso de la información de soporte en la solicitud en forma satisfactoria el sistema de la AFP le proveerá al afiliado un número de registro, bajo el status "solicitud presentada", cuyo registro podrá ser impreso directamente por el afiliado. De cumplir con los requisitos exigidos, procederá el cambio de fondo.

Las AFP procesan las solicitudes de cambio los primeros días del mes siguiente (mes $\mathrm{z}+1$, considerando que $\mathrm{z}$ fue el mes de la solicitud de cambio) y utilizan este mes para verificar e identificar los detalles de la operación, es por esto que realizan la transferencia monetaria en los primeros seis días hábiles del subsiguiente mes (mes $z+2)$. Entonces si el afiliado quiere cerciorarse que su cambio se realizó con éxito debe esperar al sétimo día para acercarse a la AFP o realizar la consulta a través de su página web, algunas administradoras suelen contactar al afiliado mediante correo electrónico para notificar que el cambio se realizó sin inconvenientes.

Fuente: Superintendencia de Banca, Seguros y AFP (https://www.sbs.gob.pe/principal/multifondos) 


\section{Anexo 3: Metodología para el efecto sobre el SPP}

$\underline{\text { Matriz de covarianzas }}$

\begin{tabular}{cccc}
\hline & Tipo 1 & Tipo 2 & Tipo 3 \\
\hline Tipo 1 & 0.006024792 & 0.01299548 & 0.024135362 \\
Tipo 2 & 0.012995484 & 0.03140235 & 0.0594886 \\
Tipo 3 & 0.024135362 & 0.0594886 & 0.119072335 \\
\hline
\end{tabular}

$\underline{\text { Resultado Risk Simulator - Escenario } 2}$

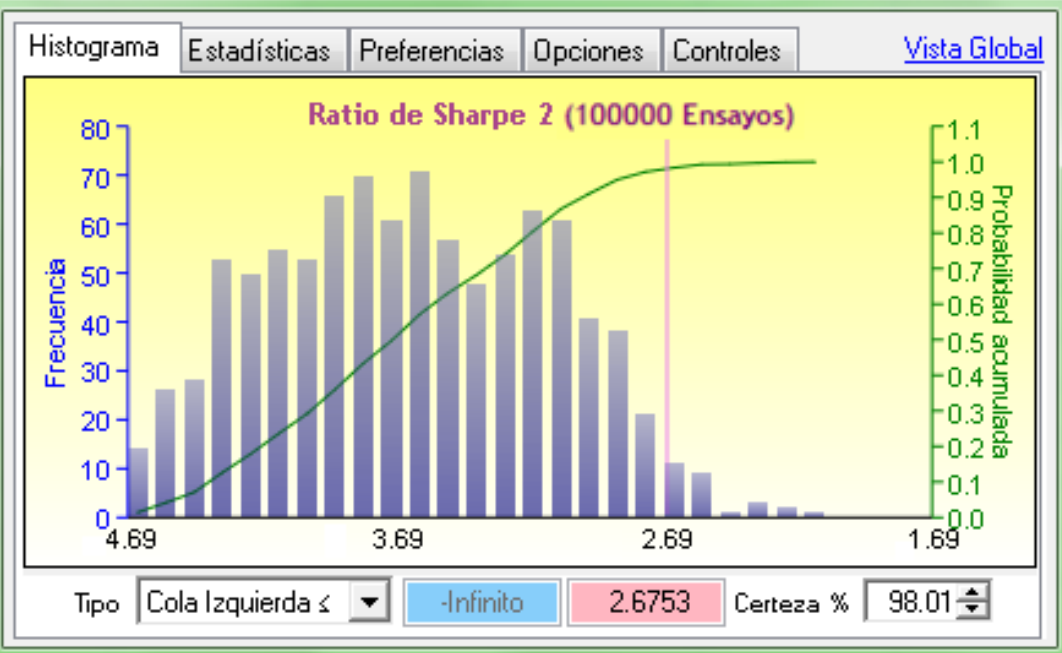




\section{Anexo 4: Datos - Paradoja FH}

\begin{tabular}{|c|c|c|c|c|c|c|c|}
\hline Fecha & $\begin{array}{c}\text { Inversión Total } \\
\text { (millones) }\end{array}$ & $\begin{array}{l}\text { Cartera Adm. SPP } \\
\text { (millones) }\end{array}$ & $\begin{array}{l}\text { Ahorro Publico } \\
\text { (millones) }\end{array}$ & $\begin{array}{c}\text { Cartera Adm (\% } \\
\text { del PBI) }\end{array}$ & $\begin{array}{c}\text { Inversión Total } \\
\text { (\% del PBI) }\end{array}$ & $\begin{array}{c}\text { Ahorro Publico } \\
\text { (\% del PBI) }\end{array}$ & $\begin{array}{l}\text { Ahorro Privado } \\
\text { (\% del PBI) }\end{array}$ \\
\hline T107 & 12070 & 50741.72778 & 132.6626896 & 0.159 & 0.199 & 0.070 & 0.129 \\
\hline T207 & 12470 & 59532.53048 & 175.3412322 & 0.186 & 0.243 & 0.112 & 0.142 \\
\hline T307 & 14050 & 61777.91971 & 143.1623776 & 0.193 & 0.211 & 0.057 & 0.172 \\
\hline T407 & 15040 & 62153.0541 & 147.4942787 & 0.194 & 0.235 & 0.028 & 0.234 \\
\hline T108 & 14810 & 60380.63395 & 165.0662933 & 0.170 & 0.228 & 0.071 & 0.122 \\
\hline T208 & 16480 & 63457.77569 & 225.3311636 & 0.178 & 0.283 & 0.096 & 0.132 \\
\hline T308 & 17910 & 56473.41988 & 206.3798123 & 0.159 & 0.273 & 0.065 & 0.161 \\
\hline T408 & 17250 & 47421.63182 & 218.2266303 & 0.133 & 0.311 & 0.052 & 0.224 \\
\hline T109 & 14720 & 50604.50932 & 147.1988516 & 0.139 & 0.211 & 0.079 & 0.108 \\
\hline T209 & 13820 & 57871.85391 & 149.1781118 & 0.159 & 0.210 & 0.070 & 0.132 \\
\hline T309 & 15580 & 63690.14571 & 113.2982726 & 0.174 & 0.182 & 0.029 & 0.152 \\
\hline T409 & 16330 & 68389.42565 & 137.3650544 & 0.187 & 0.230 & 0.021 & 0.217 \\
\hline T110 & 17020 & 68792.61158 & 170.9422054 & 0.164 & 0.219 & 0.073 & 0.118 \\
\hline T210 & 18020 & 71218.70819 & 215.1997696 & 0.170 & 0.264 & 0.086 & 0.160 \\
\hline T310 & 20160 & 76514.94887 & 193.5295298 & 0.182 & 0.243 & 0.054 & 0.156 \\
\hline T410 & 20920 & 85257.96395 & 219.138361 & 0.203 & 0.276 & 0.041 & 0.218 \\
\hline T111 & 19480 & 85048.30051 & 242.0017646 & 0.181 & 0.251 & 0.093 & 0.125 \\
\hline T211 & 20230 & 82738.41273 & 250.7291499 & 0.176 & 0.260 & 0.108 & 0.119 \\
\hline T311 & 21940 & 82302.25696 & 229.2534811 & 0.175 & 0.237 & 0.060 & 0.175 \\
\hline T411 & 22820 & 82308.36352 & 243.4287826 & 0.175 & 0.280 & 0.041 & 0.230 \\
\hline T112 & 22540 & 88859.31776 & 230.1575756 & 0.175 & 0.230 & 0.110 & 0.103 \\
\hline T212 & 23730 & 89568.95682 & 292.7952804 & 0.176 & 0.277 & 0.118 & 0.119 \\
\hline T312 & 25200 & 90907.45134 & 289.2512799 & 0.179 & 0.277 & 0.066 & 0.164 \\
\hline T412 & 26160 & 94940.46576 & 262.0388178 & 0.187 & 0.280 & 0.035 & 0.219 \\
\hline T113 & 25000 & 99710.39723 & 289.2473905 & 0.182 & 0.270 & 0.101 & 0.113 \\
\hline T213 & 26090 & 98160.30228 & 318.5178952 & 0.179 & 0.289 & 0.093 & 0.146 \\
\hline T313 & 26380 & 97132.22807 & 305.9824359 & 0.178 & 0.280 & 0.061 & 0.164 \\
\hline T413 & 26540 & 101049.8106 & 304.0978116 & 0.185 & 0.290 & 0.033 & 0.237 \\
\hline T114 & 25160 & 102231.4427 & 298.1311912 & 0.177 & 0.259 & 0.099 & 0.105 \\
\hline T214 & 25650 & 106574.2575 & 310.2805476 & 0.185 & 0.273 & 0.089 & 0.118 \\
\hline T314 & 25330 & 110362.5419 & 304.5019495 & 0.192 & 0.265 & 0.042 & 0.178 \\
\hline T414 & 26180 & 113614.5803 & 318.8971727 & 0.197 & 0.265 & 0.042 & 0.178 \\
\hline
\end{tabular}

Fuente: Superintendencia de Banca, Seguros y Administradoras Privadas de Fondos de Pensiones (SBS)

y Banco Central de Reserva del Perú (BCRP) 


\section{Anexo 5: Datos - Índice de Sharpe}

\begin{tabular}{|c|c|c|c|c|c|c|c|c|c|c|c|c|c|}
\hline Fecha & Tipo 1 & Tipo 2 & Tipo 3 & Escenario 1 & Escenario 2 & IGBVL & Fecha & Tipo 1 & Tipo 2 & Tipo 3 & scenario & scenario & IGBVL \\
\hline ene-07 & $16.12 \%$ & $29.25 \%$ & $83.39 \%$ & $29.25 \%$ & $83.39 \%$ & $5.82 \%$ & ene-11 & $5.54 \%$ & $14.63 \%$ & $27.88 \%$ & $14.63 \%$ & $14.63 \%$ & $-2.08 \%$ \\
\hline feb-07 & $18.26 \%$ & $33.74 \%$ & $85.28 \%$ & $33.74 \%$ & $85.28 \%$ & $11.13 \%$ & feb-11 & $6.98 \%$ & $17.71 \%$ & $34.15 \%$ & $17.71 \%$ & $17.71 \%$ & $-0.19 \%$ \\
\hline mar-07 & $20.46 \%$ & $38.09 \%$ & $96.20 \%$ & $38.09 \%$ & $96.20 \%$ & $13.24 \%$ & mar-11 & $4.78 \%$ & $12.29 \%$ & $24.09 \%$ & $12.29 \%$ & $12.29 \%$ & $-3.88 \%$ \\
\hline abr-07 & $23.56 \%$ & $45.97 \%$ & $109.19 \%$ & $45.97 \%$ & $109.19 \%$ & $20.50 \%$ & $a b r-11$ & $1.97 \%$ & $5.44 \%$ & $12.03 \%$ & $5.44 \%$ & $5.44 \%$ & $-10.57 \%$ \\
\hline may-07 & $23.78 \%$ & $49.70 \%$ & $108.98 \%$ & $49.70 \%$ & $108.98 \%$ & $-2.64 \%$ & may-11 & $4.23 \%$ & $9.47 \%$ & $19.64 \%$ & $9.47 \%$ & $9.47 \%$ & $9.83 \%$ \\
\hline jun-07 & $21.88 \%$ & $51.36 \%$ & $104.34 \%$ & $51.36 \%$ & $104.34 \%$ & $11.11 \%$ & jun-11 & $5.23 \%$ & $7.50 \%$ & $15.35 \%$ & $7.50 \%$ & $7.50 \%$ & $-12.46 \%$ \\
\hline jul-07 & $20.08 \%$ & $50.40 \%$ & $101.86 \%$ & $50.40 \%$ & $101.86 \%$ & $4.70 \%$ & jul-11 & $4.73 \%$ & $7.18 \%$ & $16.42 \%$ & $7.18 \%$ & $7.18 \%$ & $16.34 \%$ \\
\hline ago-07 & $15.41 \%$ & $38.91 \%$ & $76.64 \%$ & $38.91 \%$ & $76.64 \%$ & $-10.98 \%$ & ago-11 & $3.01 \%$ & $2.49 \%$ & $6.32 \%$ & $2.49 \%$ & $2.49 \%$ & $-5.76 \%$ \\
\hline sep-07 & $12.91 \%$ & $32.88 \%$ & $63.38 \%$ & $32.88 \%$ & $63.38 \%$ & $4.69 \%$ & sep-11 & $2.12 \%$ & $-1.65 \%$ & $-2.80 \%$ & $-1.65 \%$ & $-1.65 \%$ & $-11.44 \%$ \\
\hline oct-07 & $12.06 \%$ & $33.36 \%$ & $67.02 \%$ & $33.36 \%$ & $67.02 \%$ & $-0.58 \%$ & oct-11 & $-1.66 \%$ & $-9.64 \%$ & $-16.18 \%$ & $-9.64 \%$ & $-9.64 \%$ & $7.10 \%$ \\
\hline nov-07 & $9.53 \%$ & $25.01 \%$ & $49.73 \%$ & $25.01 \%$ & $49.73 \%$ & $-15.86 \%$ & nov-11 & $-1.58 \%$ & $-9.77 \%$ & $-17.34 \%$ & $-9.77 \%$ & $-9.77 \%$ & $1.44 \%$ \\
\hline dic-07 & $6.39 \%$ & $20.24 \%$ & $38.04 \%$ & $20.24 \%$ & $38.04 \%$ & $-4.01 \%$ & dic-11 & $-1.64 \%$ & $-11.26 \%$ & $-21.06 \%$ & $-11.26 \%$ & $-11.26 \%$ & $-2.20 \%$ \\
\hline ne-08 & $4.05 \%$ & $13.57 \%$ & $23.76 \%$ & $13.57 \%$ & $23.76 \%$ & $-14.35 \%$ & ene-12 & $-0.13 \%$ & $-7.52 \%$ & $-15.59 \%$ & $-7.52 \%$ & $-7.52 \%$ & $12.71 \%$ \\
\hline feb-08 & $2.93 \%$ & $7.94 \%$ & $14.46 \%$ & $7.94 \%$ & $14.46 \%$ & $18.37 \%$ & feb-12 & $1.87 \%$ & $-3.15 \%$ & $-10.23 \%$ & $-3.15 \%$ & $-3.15 \%$ & $3.56 \%$ \\
\hline mar-08 & $1.35 \%$ & $6.62 \%$ & $11.81 \%$ & $6.62 \%$ & $11.81 \%$ & $-2.14 \%$ & mar-12 & $3.35 \%$ & $-1.13 \%$ & $-6.01 \%$ & $-1.13 \%$ & $-1.13 \%$ & $3.89 \%$ \\
\hline abr-08 & $-1.00 \%$ & $-0.34 \%$ & $0.98 \%$ & $-0.34 \%$ & $0.98 \%$ & $0.24 \%$ & $a b r-12$ & $5.34 \%$ & $1.79 \%$ & $-1.64 \%$ & $1.79 \%$ & $1.79 \%$ & $-3.96 \%$ \\
\hline may-08 & $-2.59 \%$ & $-4.18 \%$ & $-5.51 \%$ & $-4.18 \%$ & $-5.51 \%$ & $-1.72 \%$ & may-12 & $4.66 \%$ & $-1.27 \%$ & $-8.03 \%$ & $-1.27 \%$ & $-1.27 \%$ & $-7.41 \%$ \\
\hline jun-08 & $-2.80 \%$ & $-4.72 \%$ & $-6.16 \%$ & $-4.72 \%$ & $-6.16 \%$ & $-4.88 \%$ & jun-12 & $4.97 \%$ & $0.73 \%$ & $-4.72 \%$ & $0.73 \%$ & $0.73 \%$ & $-3.76 \%$ \\
\hline ul-08 & $-6.08 \%$ & $-13.80 \%$ & $-19.84 \%$ & $-13.80 \%$ & $-19.84 \%$ & $-15.52 \%$ & jul-12 & $5.65 \%$ & $0.64 \%$ & $-6.54 \%$ & $0.64 \%$ & $0.64 \%$ & $-2.87 \%$ \\
\hline ago-08 & $-5.69 \%$ & $-14.07 \%$ & $-20.23 \%$ & $-14.07 \%$ & $-20.23 \%$ & $-3.47 \%$ & ago-12 & $5.19 \%$ & $1.45 \%$ & $-3.00 \%$ & $1.45 \%$ & $1.45 \%$ & $3.49 \%$ \\
\hline sep-08 & $-7.23 \%$ & $-16.70 \%$ & $-23.11 \%$ & $-16.70 \%$ & $-23.11 \%$ & $-15.35 \%$ & sep-12 & $5.61 \%$ & $3.87 \%$ & $1.82 \%$ & $3.87 \%$ & $3.87 \%$ & $6.71 \%$ \\
\hline oct-08 & $-13.69 \%$ & $-31.47 \%$ & $-43.36 \%$ & $-31.47 \%$ & $-43.36 \%$ & $-37.28 \%$ & oct-12 & $8.13 \%$ & $7.85 \%$ & $7.92 \%$ & $7.85 \%$ & $7.85 \%$ & $-4.08 \%$ \\
\hline nov-08 & $-12.47 \%$ & $-30.47 \%$ & $-43.37 \%$ & $-30.47 \%$ & $-43.37 \%$ & $4.97 \%$ & nov-12 & $8.37 \%$ & $6.84 \%$ & $5.55 \%$ & $6.84 \%$ & $6.84 \%$ & $-3.58 \%$ \\
\hline dic-08 & $-10.23 \%$ & $-26.74 \%$ & $-41.71 \%$ & $-26.74 \%$ & $-41.71 \%$ & $-4.82 \%$ & dic-12 & $9.54 \%$ & $8.89 \%$ & $7.78 \%$ & $8.89 \%$ & $8.89 \%$ & $2.92 \%$ \\
\hline ene-09 & $-7.39 \%$ & $-22.24 \%$ & $-36.70 \%$ & $-22.24 \%$ & $-36.70 \%$ & $-2.03 \%$ & ene-13 & $9.81 \%$ & $8.63 \%$ & $7.13 \%$ & $8.63 \%$ & $8.63 \%$ & $3.91 \%$ \\
\hline feb-09 & $-6.96 \%$ & $-22.90 \%$ & $-37.93 \%$ & $-22.90 \%$ & $-37.93 \%$ & $-3.38 \%$ & feb-13 & $8.87 \%$ & $4.83 \%$ & $2.11 \%$ & $4.83 \%$ & $4.83 \%$ & $-3.84 \%$ \\
\hline mar-09 & $-6.56 \%$ & $-22.94 \%$ & $-38.69 \%$ & $-22.94 \%$ & $-38.69 \%$ & $38.46 \%$ & -13 & $8.03 \%$ & $4.21 \%$ & $0.71 \%$ & $4.21 \%$ & $4.21 \%$ & $-3.65 \%$ \\
\hline abr-09 & $-3.87 \%$ & $-17.84 \%$ & $-32.75 \%$ & $-17.84 \%$ & $-32.75 \%$ & $8.03 \%$ & $a b r-13$ & $8.00 \%$ & $3.71 \%$ & $-1.32 \%$ & $3.71 \%$ & $3.71 \%$ & $-12.62 \%$ \\
\hline may-09 & $-3.17 \%$ & $-15.45 \%$ & $-29.14 \%$ & $-15.45 \%$ & $-29.14 \%$ & $34.20 \%$ & may-13 & $2 \%$ & $6.17 \%$ & $3.32 \%$ & $6.17 \%$ & $6.17 \%$ & $-7.51 \%$ \\
\hline jun-09 & $-1.15 \%$ & $-12.04 \%$ & $-24.03 \%$ & $-12.04 \%$ & $-24.03 \%$ & $-2.48 \%$ & jun-13 & $3.48 \%$ & $1.71 \%$ & $0.54 \%$ & $1.71 \%$ & $1.71 \%$ & $-3.12 \%$ \\
\hline jul-09 & $3.10 \%$ & $-4.62 \%$ & $-15.04 \%$ & $-4.62 \%$ & $-15.04 \%$ & $7.90 \%$ & jul-13 & $1.24 \%$ & $-0.41 \%$ & $-0.48 \%$ & $-0.41 \%$ & $-0.41 \%$ & $-2.77 \%$ \\
\hline ago-09 & $5.63 \%$ & $3.04 \%$ & $-4.35 \%$ & $3.04 \%$ & $-4.35 \%$ & $-0.97 \%$ & -13 & $0.08 \%$ & $-0.43 \%$ & $0.53 \%$ & $-0.43 \%$ & $-0.43 \%$ & $10.14 \%$ \\
\hline sep-09 & $10.02 \%$ & $11.26 \%$ & $6.71 \%$ & $11.26 \%$ & $6.71 \%$ & $8.52 \%$ & sep-13 & $-1.24 \%$ & $-2.13 \%$ & $-2.08 \%$ & $-2.13 \%$ & $-2.13 \%$ & $-4.40 \%$ \\
\hline oct-09 & $18.68 \%$ & $35.45 \%$ & $45.41 \%$ & $45 \%$ & $45.41 \%$ & -6.1 & & $-1.33 \%$ & $-1.85 \%$ & $-3.06 \%$ & $-1.85 \%$ & & $2.53 \%$ \\
\hline nov-09 & $17.95 \%$ & $37.90 \%$ & $53.27 \%$ & $37.90 \%$ & $53.27 \%$ & $-0.59 \%$ & nov-13 & $-1.55 \%$ & $-1.27 \%$ & $-0.92 \%$ & $-1.27 \%$ & $-1.27 \%$ & $-6.87 \%$ \\
\hline dic-09 & $16.08 \%$ & $32.88 \%$ & $52.10 \%$ & $32.88 \%$ & $52.10 \%$ & $0.27 \%$ & & $-2.69 \%$ & $-2.82 \%$ & $-2.47 \%$ & $-2.82 \%$ & $-2.82 \%$ & $3.64 \%$ \\
\hline ene-10 & $13.83 \%$ & $30.16 \%$ & $52.12 \%$ & $30.16 \%$ & $52.12 \%$ & $1.93 \%$ & ene-14 & $-3.71 \%$ & $-4.44 \%$ & $-4.74 \%$ & $-4.44 \%$ & $-3.71 \%$ & $-1.91 \%$ \\
\hline feb-10 & $11.09 \%$ & $26.19 \%$ & $46.27 \%$ & $26.19 \%$ & $46.27 \%$ & $-3.03 \%$ & feb-14 & $-5.79 \%$ & $-6.32 \%$ & $-8.11 \%$ & $-6.32 \%$ & $-5.79 \%$ & $-0.07 \%$ \\
\hline mar-10 & $11.47 \%$ & $28.56 \%$ & $49.48 \%$ & $28.56 \%$ & $49.48 \%$ & $8.05 \%$ & mar-14 & $-4.94 \%$ & $-5.24 \%$ & $-7.26 \%$ & $-5.24 \%$ & $-4.94 \%$ & $-7.40 \%$ \\
\hline abr-10 & $8.88 \%$ & $23.52 \%$ & $41.48 \%$ & $23.52 \%$ & $41.48 \%$ & $4.71 \%$ & $a b r-14$ & $-4.88 \%$ & $-4.33 \%$ & $-5.73 \%$ & $-4.33 \%$ & $-4.88 \%$ & $8.60 \%$ \\
\hline may-10 & $6.18 \%$ & $15.59 \%$ & $25.36 \%$ & $15.59 \%$ & $25.36 \%$ & $-8.55 \%$ & may-14 & $-4.18 \%$ & $-3.23 \%$ & $-3.64 \%$ & $-3.23 \%$ & $-4.18 \%$ & $1.45 \%$ \\
\hline jun-10 & $3.99 \%$ & $11.70 \%$ & $16.53 \%$ & $11.70 \%$ & $16.53 \%$ & $-3.47 \%$ & jun-14 & $0.43 \%$ & $2.67 \%$ & $2.22 \%$ & $2.67 \%$ & $0.43 \%$ & $5.77 \%$ \\
\hline jul-10 & $4.35 \%$ & $12.40 \%$ & $16.95 \%$ & $12.40 \%$ & $16.95 \%$ & $2.08 \%$ & & $1.85 \%$ & $4.48 \%$ & $4.62 \%$ & $4.48 \%$ & $1.85 \%$ & $1.22 \%$ \\
\hline ago-10 & $5.40 \%$ & $12.19 \%$ & $16.17 \%$ & $12.19 \%$ & $16.17 \%$ & $6.15 \%$ & ago-14 & $3.47 \%$ & $5.38 \%$ & $3.93 \%$ & $5.38 \%$ & $3.47 \%$ & $0.86 \%$ \\
\hline-10 & $4.48 \%$ & $11.50 \%$ & $17.86 \%$ & $11.50 \%$ & $17.86 \%$ & $17.91 \%$ & & $5.04 \%$ & $6.61 \%$ & $5.24 \%$ & $6.61 \%$ & $5.04 \%$ & $-4.61 \%$ \\
\hline oct-10 & $6.05 \%$ & $13.97 \%$ & $22.63 \%$ & $13.97 \%$ & $22.63 \%$ & $7.58 \%$ & oc & $3.75 \%$ & $3.62 \%$ & $1.59 \%$ & $3.62 \%$ & $3.75 \%$ & $-3.41 \%$ \\
\hline nov-10 & $6.04 \%$ & $14.96 \%$ & $26.97 \%$ & $14.96 \%$ & $26.97 \%$ & $8.50 \%$ & nov-14 & $4.15 \%$ & $4.78 \%$ & $2.72 \%$ & $4.78 \%$ & $4.15 \%$ & $-3.62 \%$ \\
\hline dic-10 & $5.71 \%$ & $16.03 \%$ & $31.79 \%$ & $16.03 \%$ & $31.79 \%$ & $12.08 \%$ & dic-14 & $4.44 \%$ & $5.52 \%$ & $3.36 \%$ & $5.52 \%$ & $4.44 \%$ & $-2.07 \%$ \\
\hline
\end{tabular}

Fuente: Superintendencia de Banca, Seguros y Administradoras Privadas de Fondos de Pensiones (SBS) 